\title{
SHAPE OPTIMIZATION OF ROCKFILL DAM WITH RUBIK CUBE REPRODUCTION BASED MULTI- OBJECTIVE PARTICLE SWARM ALGORITHM
}

\author{
Ali Mahmoud ${ }^{\mathrm{a}}$ and Xiaohui Yuan ${ }^{\mathrm{b} *}$

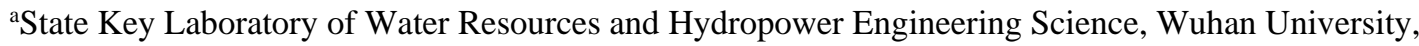 \\ Wuhan, China, e-mail: a.mahmoud@whu.edu.cn \\ ${ }^{\mathrm{b}}$ School of Civil and Hydraulic Engineering, Huazhong University of Science and Technology, Wuhan, \\ China, e-mail: yxh71@163.com
}

Received Date: September 22, 2020; Revised Date: April 27, 2021; Acceptance Date: October 29, 2021

\begin{abstract}
A rockfill dam's quality and its economic aspects are inextricably interwoven with each other. Approaching the optimal design of a rockfill dam paves the path to achieve the best quality with the fewest expenses. Choosing the Sardasht rockfill dam as a case study, two semi-empirical models are presented for seepage and safety factor. These two models, together with construction costs, were employed as three objective functions for the Sardasht rockfill dam's shape optimization. Optimization was handled using a robust multi-objective particle swarm optimization algorithm (RCR-MOPSO). A new reproducing method inspired by a Rubik's cube shape (RCR) and NSGA-III are building blocks of RCR-MOPSO. Three benchmark problems and two real-world problems were solved using RCR-MOPSO and compared with NSGA-III and MOPSO to ensure the performance of RCR-MOPSO. The solution quality and performance of RCR-MOPSO are significantly better than the original MOPSO and close to NSGA-III. Nevertheless, RCR-MOPSO recorded a $38 \%$ shorter runtime than NSGA-III. RCR-MOPSO presented a set of non-dominated solutions as final results for the Sardasht rockfill dam shape optimization. Due to the defined constraints, all solutions dominate the original design. Regarding the final results, compared with Sardasht dam's original design, the construction price was reduced by $31.12 \%$ on average, while seepage and safety factor improved by $15.84 \%$ and $27.78 \%$ on average, respectively.
\end{abstract}

Keywords: Earth dams, Design methods \& aids, Safety \& hazards

\section{List of Notation}

\begin{tabular}{|c|c|c|c|c|c|}
\hline Parameter & definition & unit & Parameter & definition & unit \\
\hline $\mathbf{H}_{\mathbf{C}}$ & Clay core height & $\mathrm{m}$ & FOS & Factor Of Safety & ---- \\
\hline $\mathbf{H}_{\mathrm{Cr}}$ & Height of the dam & $\mathrm{m}$ & $\mathrm{k}$ & $\begin{array}{l}\text { hydraulic conductivity of } \\
\text { clay core materials }\end{array}$ & $\mathrm{m} /$ year \\
\hline $\mathbf{S}_{\mathrm{C}}$ & Angle of clay core & Radian & $\mathrm{h}$ & $\begin{array}{l}\text { Normal water level in } \\
\text { upstream }\end{array}$ & meter \\
\hline$S_{U c}$ & $\begin{array}{l}\text { Upstream angle of } \\
\text { dam crust }\end{array}$ & Radian & $\mathrm{q}$ & $\begin{array}{l}\text { Discharge through clay core } \\
\text { in one-meter width }\end{array}$ & $\mathrm{m}^{2} /$ year \\
\hline$S_{\mathrm{Dc}}$ & $\begin{array}{l}\text { Downstream angle of } \\
\text { dam crust }\end{array}$ & Radian & $\mathrm{n}$ & $\begin{array}{l}\text { Number of decision } \\
\text { variables }\end{array}$ & ---- \\
\hline $\mathbf{d}_{\mathbf{C}}$ & $\begin{array}{l}\text { Width of clay core at } \\
\text { dam crest }\end{array}$ & M & M & $\begin{array}{l}\text { Number of Objective } \\
\text { functions }\end{array}$ & ---- \\
\hline $\mathbf{d}_{\mathrm{Cr}}$ & $\begin{array}{l}\text { Width of the dam } \\
\text { crest }\end{array}$ & M & $\Theta$ & n-dimensional search space & ---- \\
\hline $\mathbf{A}_{1}$ & $\begin{array}{l}\text { Area is occupied by } \\
\text { Clay core }\end{array}$ & $\mathrm{m}^{2}$ & $\Psi$ & m-dimensional vector space & ---- \\
\hline $\mathbf{A}_{2}$ & $\begin{array}{l}\text { Area is occupied by } \\
\text { Crust }\end{array}$ & $\mathrm{m}^{2}$ & $\mathrm{x}_{\mathrm{i}}^{\max }$ & $\begin{array}{l}\text { upper bound of ith decision } \\
\text { variable }\end{array}$ & ---- \\
\hline
\end{tabular}




\begin{tabular}{|c|c|c|c|c|c|}
\hline Parameter & definition & unit & Parameter & definition & unit \\
\hline $\mathbf{P}_{\mathbf{C}}$ & $\begin{array}{l}\text { Units price of Clay } \\
\text { core materials }\end{array}$ & Price $/ \mathrm{m}^{3}$ & $\mathrm{x}_{\mathrm{i}}^{\min }$ & $\begin{array}{l}\text { lower bound of ith decision } \\
\text { variable }\end{array}$ & ---- \\
\hline $\mathbf{P}_{\mathrm{Cr}}$ & $\begin{array}{l}\text { Units price of Crust } \\
\text { materials }\end{array}$ & Price $/ \mathrm{m}^{3}$ & $\mathrm{~h}_{\mathrm{k}}(\mathrm{x})$ & equality constraints & ---- \\
\hline $\mathbf{P}$ & $\begin{array}{l}\text { Total price of } \\
\text { construction }\end{array}$ & price & $g_{j}(x)$ & inequality constraints & ---- \\
\hline$\varphi_{\mathrm{C}}$ & $\begin{array}{l}\text { Internal friction angle } \\
\text { of clay core materials }\end{array}$ & Radian & $\mathrm{e}$ & $\begin{array}{l}\text { Number of equality } \\
\text { constraints }\end{array}$ & ---- \\
\hline$\varphi_{\mathrm{Cr}}$ & $\begin{array}{l}\text { Internal friction angle } \\
\text { of crust material s }\end{array}$ & Radian & $\mathrm{z}$ & $\begin{array}{l}\text { Number of inequality } \\
\text { constraints }\end{array}$ & ---- \\
\hline$\gamma_{C}$ & $\begin{array}{l}\text { special unit weight of } \\
\text { clay core materials }\end{array}$ & $\mathrm{kg} / \mathrm{m}^{3}$ & $\mathrm{~A}$ & approximation front & ---- \\
\hline$\gamma_{\mathrm{Cr}}$ & $\begin{array}{l}\text { special unit weight of } \\
\text { crust materials }\end{array}$ & $\mathrm{kg} / \mathrm{m}^{3}$ & a & an objective vector in $\mathrm{A}$ & ---- \\
\hline $\mathrm{C}_{\mathrm{C}}$ & $\begin{array}{l}\text { cohesion of clay core } \\
\text { materials }\end{array}$ & $\mathrm{kg} / \mathrm{m}^{2}$ & $\mathrm{~T}$ & True Pareto & ---- \\
\hline
\end{tabular}

\section{Introduction}

Optimization plays a significant role in human life. Humankind is always seeking to achieve one or several optimum goals in a problem. Approaching maximum benefit, maximum efficiency, or finding the shortest distance or minimum possible time in solving a problem are some routine optimization problems. In mathematics, an optimization problem is finding the best solution with maximum fitness [1]. Due to the number of goals (i.e., objectives) in an optimization problem, these problems are divided into single and multi-objective problems.

The present research aims to approach the optimal design of a rockfill dam by solving a multi-objective optimization problem. To this end, the rockfill dam shape optimization problem is thoughtfully developed, and an enhanced Multi-Objective Particle Swarm Optimization algorithm (MOPSO), termed RCR-MOPSO, is introduced and utilized for solving the proposed MOP. Accordingly, the literature review corresponding to this research topic could be divided into two categories: 1) Studies on proposing enhanced optimization algorithms. 2) studies on rockfill dam shape optimization.

The Multi-Objective Particle Swarm Optimization algorithm (MOPSO) is one of the most popular optimization algorithms due to its simplicity and short computational time. Accordingly, many scholars use MOPSO for solving optimization problems in many different fields (e.g., [2], [3], [4], [5], [6]). To reduce the computational time of MOPSO, Curtis, and Lewis [7] tried to reduce the required evaluations for the objective function without degrading solution quality. This issue was handled by restricting the repository size and reducing the trial solution population size. They found that the number of function evaluations can be reduced by $66.7 \%$ without significantly reducing solutions' quality. This study expressed the importance of algorithm operation parameters. To provide a better diversity for swarm optimization, Pan et al. [8] proposed Diversity Enhanced MOPSO (DEMPSO). This robust algorithm first simplified the leader-orientation formulation and later proposed a new method for decision variable analysis, which improved the diversity. Finally, they presented an adaptive two-fold leader selection strategy. They found that their algorithm improved the diversity maintainability in high-dimensional spaces compared to some other state-of-the-art decomposition-based and dominated-based evolutionary algorithms.

A brief review of mentioned studies reveals the importance of enhancement in the existing optimization algorithms in general and MOPSO in particular. Accordingly, the 
present study introduces an enhanced MOPSO, namely the Rubik's Cubic Reproduction MOPSO (RCR-MOPSO). This novel algorithm exploits a new parent reproducing method inspired by Rubik's cube shape. Furthermore, RCR-MOPSO takes advantage of NSGA-III to provide more diversity and convergence in solutions. Comparing the proposed methods in this research with previous studies magnifies the novelty of the obtained techniques for improving MOPSO in this study.

Along with developing artificial intelligence and optimization methods, many researchers used optimization in dam body design, and they tried to optimize the different varieties of dam bodies. Xu et al. [9] optimized suitable soil material apportion in the right part of the cross-section domain when hydraulic conductivity controlled. They used numerical methods to optimize the objective function. Cai et al. [10] investigated the shape optimization of cement, sand, and gravel dams (CSG). Haghigatandish et al. [11] optimized the dimensions of an earth dam using the Shuffled Complex Evolution (SCE) method; they used Geo-studio to simulate the earth dam. Subsequently, according to the Geo-studio results, they used linear regression to extract the optimization objective functions. After optimization with SCE, they submitted an empirical model to design earth dams. Mohammadi et al. [12] employed a genetic algorithm to optimize the seepage in the clay core of an earth dam. In order to produce the objective function, they have employed SEEP/W to simulate the seepage through the clay core. Likewise, the same methodology has been adopted by Montaseri et al. [13] to minimize the seepage in the clay core of a rockfill dam. Ghoddosy et al. [14] optimized earth dam dimensions with SCE and LINGO11; they also used Geo-studio as a simulator and extracted the objective function and constraints with linear regression simulator's results. Reviewing past studies in this area reveals that safety, construction price, and seepage through the rock-fill dam are three essential parameters involved in the rock-fill dam shape optimization. These parameters can be defined as functions of a MOP based on reliable experimental or numerical results. The designated literature review reveals that researchers have used this method in past studies [11-14]. Due to the massive volume of rock-fill dams, it is not always possible to have experimental results. To provide a set of reliable results, researchers used SEEP/W and SLOP/W to calculate FOS and seepage in a rockfill dam [11,13-15] which confirms the reliability of these software in calculating FOS and seepage.

This study aims at approaching the optimal design of a rock-fill dam with maximum Factor of Safety (FOS), minimum seepage, and construction costs. In order to identify this multi-objective optimization problem, a rockfill dam was simulated in SEEP/W and SLPO/W to study seepage and FOS, respectively. It should be noticed that SEEP/W and SLPO/W are two popular software in the GEO-studio package that takes advantage of finite elements for its calculation. Subsequently, utilizing the simulation results, two new semi-empirical models are presented to calculate the FOS and seepage in which FOS and seepage are defined as functions of clay core angle and crust shell angles. Likewise, the clay core and crust shell area were calculated as a function of their angles, which are utilized to calculate the construction costs of the rockfill dam. Eventually, FOS, seepage, and the construction price are employed as objective functions of the defined MOP, which is solved by the proposed algorithm (i.e., RCR-MOPSO). To evaluate the performance of the proposed algorithm, two popular multi-objective algorithms, including MOPSO and Non-dominated Genetic Sorting Algorithm-III (NSGA-III), are employed for solving the rockfill dam shape multi-objective optimization problem. Besides the defined problem in this study, the compared algorithms are utilized for solving two standard benchmark problems and a real-world multi-objective problem, and their final results are thoughtfully compared. 


\section{Problem Statement}

The present study aims to approach the optimal design of a rockfill dam by modifying its clay core and crust shell angles. The satisfactory solutions in this optimization problem are achieved by approaching maximum FOS in downstream slop of rockfill dam's crust, minimum seepage through its clay core, and minimum construction costs. In order to identify the objective functions for FOS and seepage, the Sardasht rockfill dam is simulated in SLOP/W and SEEP/W, respectively. Subsequently, based on SLOP/W results and influential parameters of FOS, a semi-empirical model is proposed to calculate the FOS as a function of clay core and downstream slop angles, using multi non-linear regression in SPSS. Likewise, based on SEEP/W results and influential parameters of seepage, another model is proposed by the same technique to calculate the seepage as a function of clay core angle. Besides the two proposed semi-empirical models, the area of rockfill dam clay core and crust is calculated as a clay core and downstream crust angle. After that, by multiplying the unit price of clay core and crust shell on their area, the construction cost of Sardasht rockfill dam in the biggest cross-section is calculated.

\section{Case Study}

To provide a better simulation and have actual data, this study is applied to a real dam. The Sardasht rockfill dam is chosen as a case study in this research. It is one of the frontier-situated dams in the Middle East and is constructed in the northwest of Iran. The dam's crest length is 278 meters, and its maximum height at the river section is 108 meters. The width of the dam is 12 meters at the crest and 463 meters at the widest point at the foundation level. The Sardasht dam is built on bedrock consisting of alternating layers of slates and phyllite metamorphic rocks [16]. The location and the biggest cross-section of the Sardasht dam are shown in Figure 1.

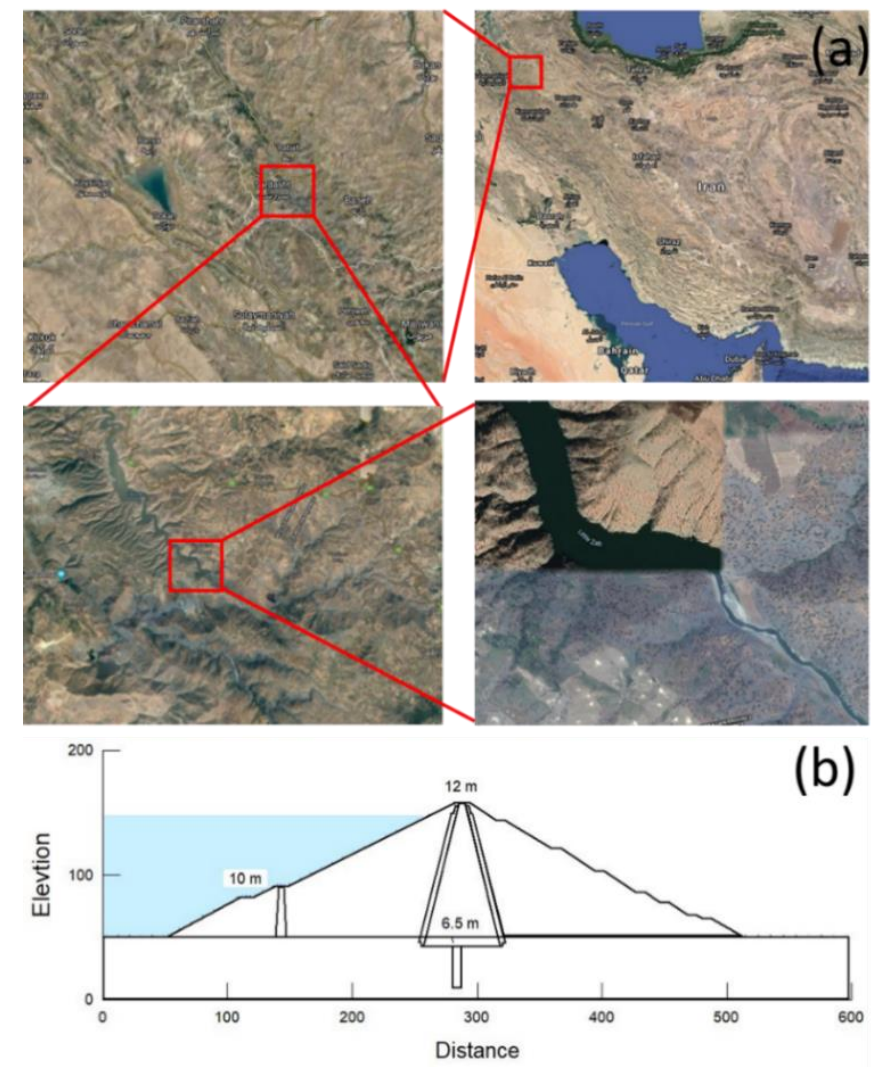

Figure 1: Sardasht rockfill dam (a): Location (b): Biggest cross-section 
This dam was designed based on designer experience and a trial-and-error method. Concerning hydrological studies, the normal upstream water level was calculated as 98 meters. The designers considered 10 meters for freeboard, and the maximum height of the dam is calculated as 108 meters. The final plan details are shown in Table 1 [17]. In order to simulate the FOS and seepage, the shape of the Sardasht rockfill dam is modelled in SLOP/W and SEEP/W.

Table 1. Sardasht Rockfill Dam Final Plan Details

\begin{tabular}{ll}
\hline Parameter & Final Plan \\
\hline Maximum height & 108 (meter) \\
Normal water level & 98 (meter) \\
Clay core height & 107 (meter) \\
Crust shell Downstream angle & $64.85\left(^{\circ}\right)$ \\
Crust shell upstream angle & $63.67\left(^{\circ}\right)$ \\
Clay core angle(both side) & $24\left(^{\circ}\right)$ \\
The factor of safety for downstream slope & $1.85($ unitless $)$ \\
Seepage through core & 0.009 (Million $\mathrm{m}^{3} /$ year) \\
Price of construction & 404585 (unit of price) \\
\hline
\end{tabular}

Even after this plan was approved by the consulting party, during the construction period, the downstream slope was stabilized by seven terraces to provide a factor of safety more than 2. This operation significantly increased the cost and time of construction. The terraces are observable in Figure 1(b). the present study aims to approach an optimal design of the Sardash rockfill dam with maximum FOS in downstream slop, minimum construction costs, and seepage through clay core. To this end, each of these objectives are defined in the following sections.

\section{Construction Costs}

The total construction costs of a rockfill dam directly depend on material volume. In a rockfill dam with different types of materials, like clay core, rockfill crust, filter, transition, drain, and riprap, due to the massive volume of clay core and crust shell, the effect of other materials on construction costs could be neglected. The area occupied by crust shell and clay core in a rockfill dam cross-section, as a function of $S_{C}, S_{U c}$ and $S_{D c}$, can be calculated using the following equations:

$$
\begin{gathered}
A_{1}=H_{C}^{2} \times\left(\tan S_{C}+\frac{d_{c}}{H_{c}}\right) \\
A_{2}=\frac{H_{C r}^{2}}{2} \times\left(\tan S_{U c}+\tan S_{D c}+2 \times \frac{d_{C r}}{H_{C r}}\right)-A_{1}
\end{gathered}
$$

If $P_{C}$ and $P_{C r}$ are the unit price of clay core and crust shell materials, the following equation calculates the price of construction:

$$
P=A_{1} \times P_{C}+A_{2} \times P_{C r}
$$


Regarding the geotechnical study of Sardasht rockfill dam $P_{C}$ and $P_{C r}$ Respectively are considered 16 and 7 units of price [17]. Moreover $S_{C}, S_{U c}$ and $S_{D c}$, are illustrated in Figure 2.

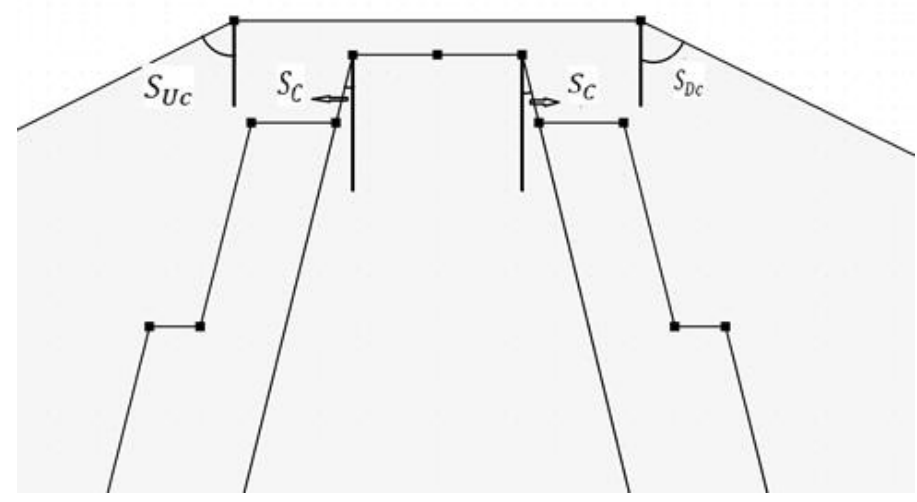

Figure 2. Illustration of clay core angle $\left(S_{C}\right)$, upstream crust angle $\left(S_{U c}\right)$ and downstream angle $\left(S_{D c}\right)$

\section{The Factor of Safety of Downstream Slop}

The Factor of Safety or FOS is studied for the downstream slope of the biggest cross-section of the Sardasht rockfill dam. SLOP/W was employed for this issue, and these simulations were repeated 1800 times with four different sets of material types, fifteen different angles of clay core $\left(S_{C}\right)$ and thirty different angles of downstream crust shell $\left(S_{D c}\right) .(1800=30 * 15 * 4)$

During simulations, there was steady-state flow at the normal water level. Table 2 shows the four physical parameters applied to different types of soil. These parameters were extracted from the geological study of the Sardasht rockfill dam and allocated to different borrowing pits around the dam site [17]. The simulated dam in SLOP/W is illustrated in Figure 3.

Table 2. Four Different Sets of Material Types Are Used in SLOP/W for Simulating FOS [17]

\begin{tabular}{lcccccc}
\hline Types & $\begin{array}{c}\text { Model } \\
\text { Part }\end{array}$ & Material & $\begin{array}{c}\text { Saturated } \\
\text { Unit Weight } \\
\text { (KN/M3) }\end{array}$ & $\begin{array}{c}\text { Unsaturated } \\
\text { Unit Weight } \\
\text { (KN/M3) }\end{array}$ & $\begin{array}{c}\text { Cohesion } \\
\text { (Kpa) }\end{array}$ & $\begin{array}{c}\text { Phi } \\
\text { (degree) }\end{array}$ \\
\hline Type 1 & clay core & clay & 24 & 19 & 11 & 15 \\
& crust & silty sand & 26 & 23.5 & 75 & 37 \\
& drain & gravel & 22 & 20 & 1 & 40 \\
& filter & sand & 22 & 20 & 1 & 35 \\
type 2 & foundation & silty clay & 28 & 26 & 100 & 32 \\
& clay core & clay & 22.8 & 20.8 & 29.42 & 30 \\
& crust & silty sand & 24.6 & 22.6 & 4.9 & 40 \\
& drain & gravel & 22 & 20 & 1 & 40 \\
& filter & sand & 22 & 20 & 1 & 35 \\
type 3 & foundation & silty clay & 28 & 26 & 100 & 32 \\
& clay core & clay & 18 & 16 & 40 & 35 \\
& crust & silty sand & 24.5 & 23.5 & 5 & 43 \\
& drain & gravel & 22 & 20 & 1 & 40 \\
& filter & sand & 22 & 20 & 1 & 35 \\
& foundation & silty clay & 28 & 26 & 100 & 32 \\
\hline
\end{tabular}




\begin{tabular}{lcccccc}
\hline Types & $\begin{array}{c}\text { Model } \\
\text { Part }\end{array}$ & Material & $\begin{array}{c}\text { Saturated } \\
\text { Unit Weight } \\
\text { (KN/M3) }\end{array}$ & $\begin{array}{c}\text { Unsaturated } \\
\text { Unit Weight } \\
\text { (KN/M3) }\end{array}$ & $\begin{array}{c}\text { Cohesion } \\
\text { (Kpa) }\end{array}$ & $\begin{array}{c}\text { Phi } \\
\text { (degree) }\end{array}$ \\
\hline Type 4 & clay core & clay & 18 & 16 & 40 & 15 \\
& crust & silty sand & 21 & 20.6 & 13 & 30 \\
& drain & gravel & 22 & 20 & 1 & 40 \\
& filter & sand & 22 & 20 & 1 & 35 \\
& foundation & silty clay & 28 & 26 & 100 & 32 \\
\hline
\end{tabular}

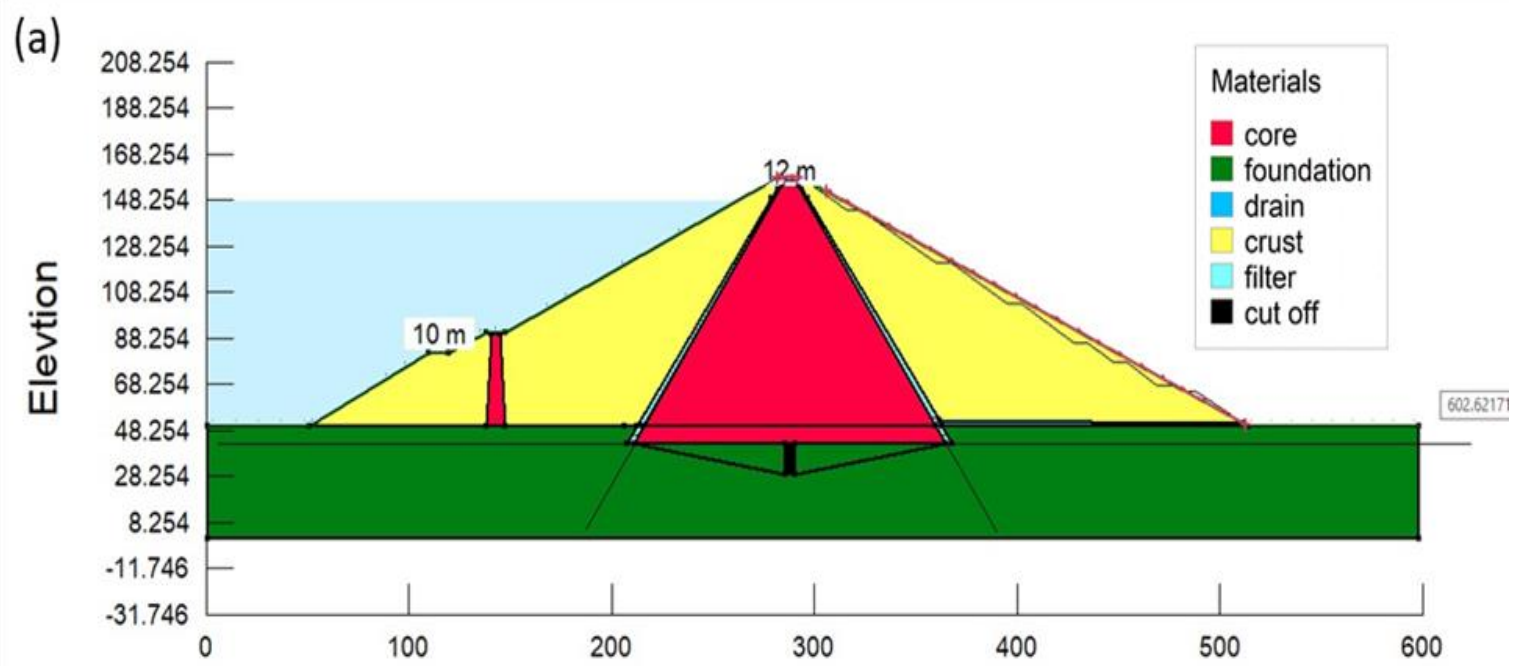

(b)

Distance
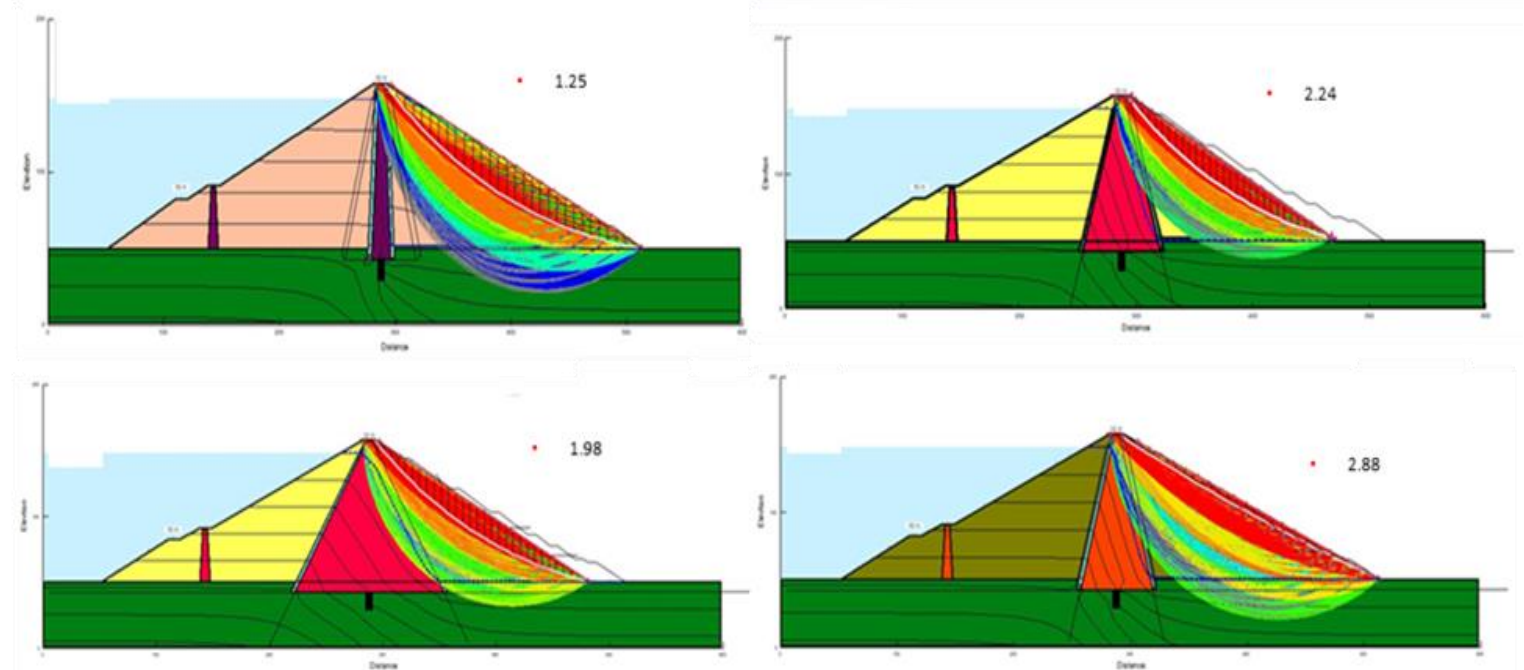

Figure 3. (a): The simulation of Sardash rockfill dam in SLOP/W. (b): Illustration of for different simulations with different $S_{c}, S_{D c}$, and material types

Regarding SLOP/W outputs and by non-linear regression in SPSS, Equation (4) is extracted as a semi-empirical model to calculate FOS in a rockfill dam as a function of $S_{C}$ and $S_{D c}$, material physical parameters (internal friction angle, unit weight, and cohesion), and, finally, dam and clay core height. The R squared of this model is 0.944 ; this number, in addition to a small amount of residual mean squares, emphasizes the model's confidence. Detailed results of the non-linear regression are shown in Table 3, while the difference between simulated FOS in SLOP/W and calculated FOS by Equation (4) is shown in Figure 4. 


$$
\begin{aligned}
\text { FOS }=-0.374 & \times\left(\tan S_{C} \times \tan \varphi_{C}\right)+7.428 \times \frac{C_{C}}{\gamma_{C} \times H_{C}} \\
+ & 0.439 \times\left(\tan S_{D c} \times \tan \varphi_{C r}\right)+7.964 \times \frac{C_{C r}}{\gamma_{C r} \times H}+0.866
\end{aligned}
$$

It should be noticed that the upstream slope is reinforced by riprap and other slop stabilities reinforcement. After that, in the present study, FOS is calculated as a function of $S_{C}, S_{U c}$. Moreover, The higher sensitivity of downstream slope is expressed in united states army standard [18].

Table 3. ANOVA Analysis for the Factor of Safety

\begin{tabular}{llll}
\hline Source & Sum of Squares & df & Mean Squares \\
\hline Regression & 6387.726286 & 5 & 1277.545257 \\
Residual & 25.024986 & 1795 & 0.013941 \\
Uncorrected Total & 6412.751273 & 1800 & \\
Corrected Total & 450.702323 & 1799 & \\
\multicolumn{4}{c}{ a. R squared $=1$ - (Residual Sum of Squares) / (Corrected Sum of Squares) $=0.944$} \\
\hline
\end{tabular}
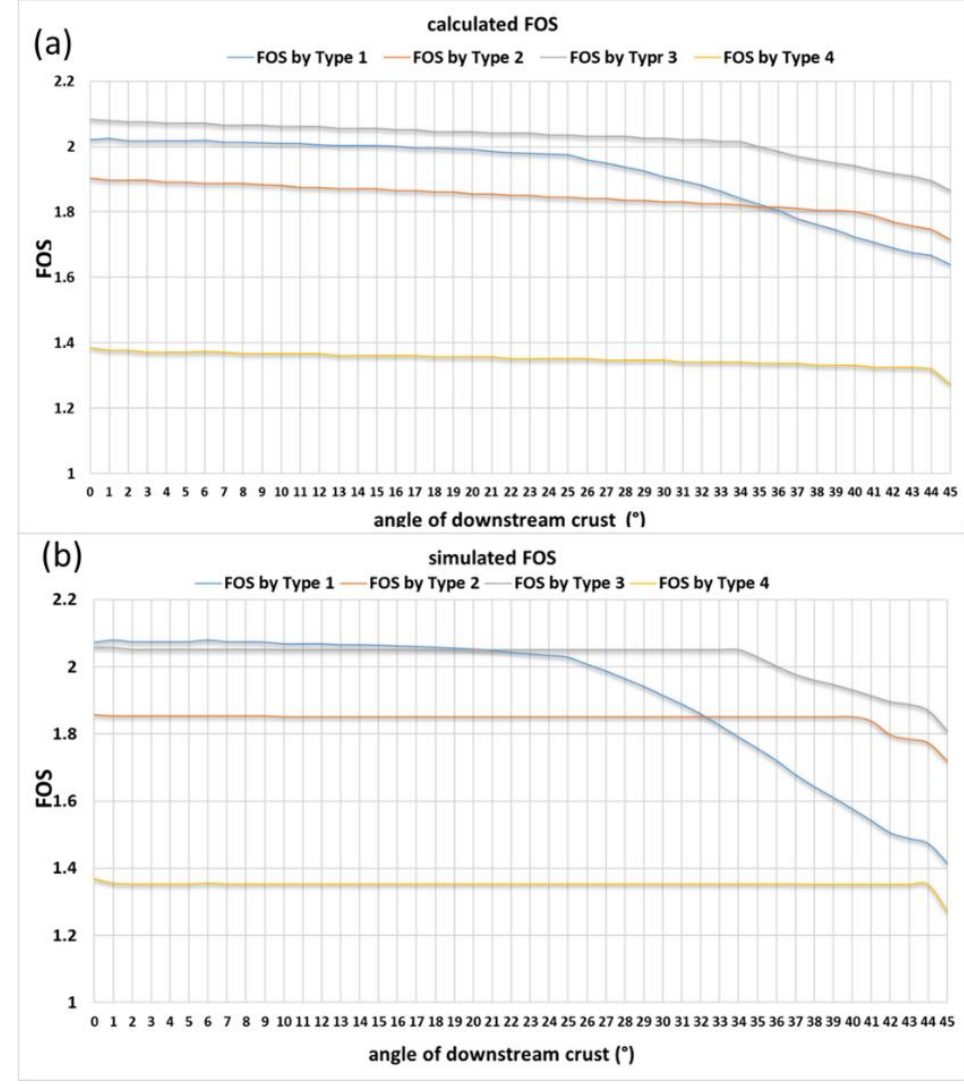

Figure 4. (a): Simulated FOS in SLOP/W for different materials in different $\mathrm{S}_{\mathrm{Ds} .}(\mathrm{b})$ : Calculated FOS by Equation (4)

Concerning Equation (4), it is worth it to perform a sensitivity analysis. It should be noticed that due to the goal of this study as the shape optimization of a rockfill dam, as well as the discrete nature of physical parameters are involving in FOS, $S_{C}$ and $S_{D c}$ by virtue of their 
contribution to rockfill dam shape are considered as independent variables in FOS optimization. Moreover, physical parameters were chosen based on the borrowing pit, in the case of the Sardasht dam, which could be only one of four different types (Table 2).

\section{Seepage Through Clay Core}

The seepage through a rockfill dam is primarily dependent on the clay core width and material. Due to the minor hydraulic conductivity of clay, the flow velocity is limited by the clay core in a rockfill dam. In this study, for this issue, the clay core was simulated in SEEP/W as an isotropic earth dam on an unpenetrated bed. This simulation was repeated 228 times with six different types of materials and 38 different $\mathrm{S}_{\mathrm{C}}$. Table 4 shows the hydraulic conductivities of six different types of clay which is employed in SEEP/W simulations. According to the Sardasht dam geotechnical studies, the hydraulic conductivity of two chosen clay borrowing pits is 0.094608 and $0.15768 \mathrm{~m} /$ year [17]; the remaining clay types were presumed to provide a better data set and, consequently, a better semi-empirical model.

Table 4. Different Hydraulic Conductivity in Seepage Simulations

\begin{tabular}{ll}
\hline Type & Hydraulic Conductivity (m/year) \\
\hline 1 & 0.07884 \\
2 & 0.094608 \\
3 & 0.126144 \\
4 & 0.15768 \\
5 & 0.189216 \\
6 & 0.220752 \\
\hline
\end{tabular}
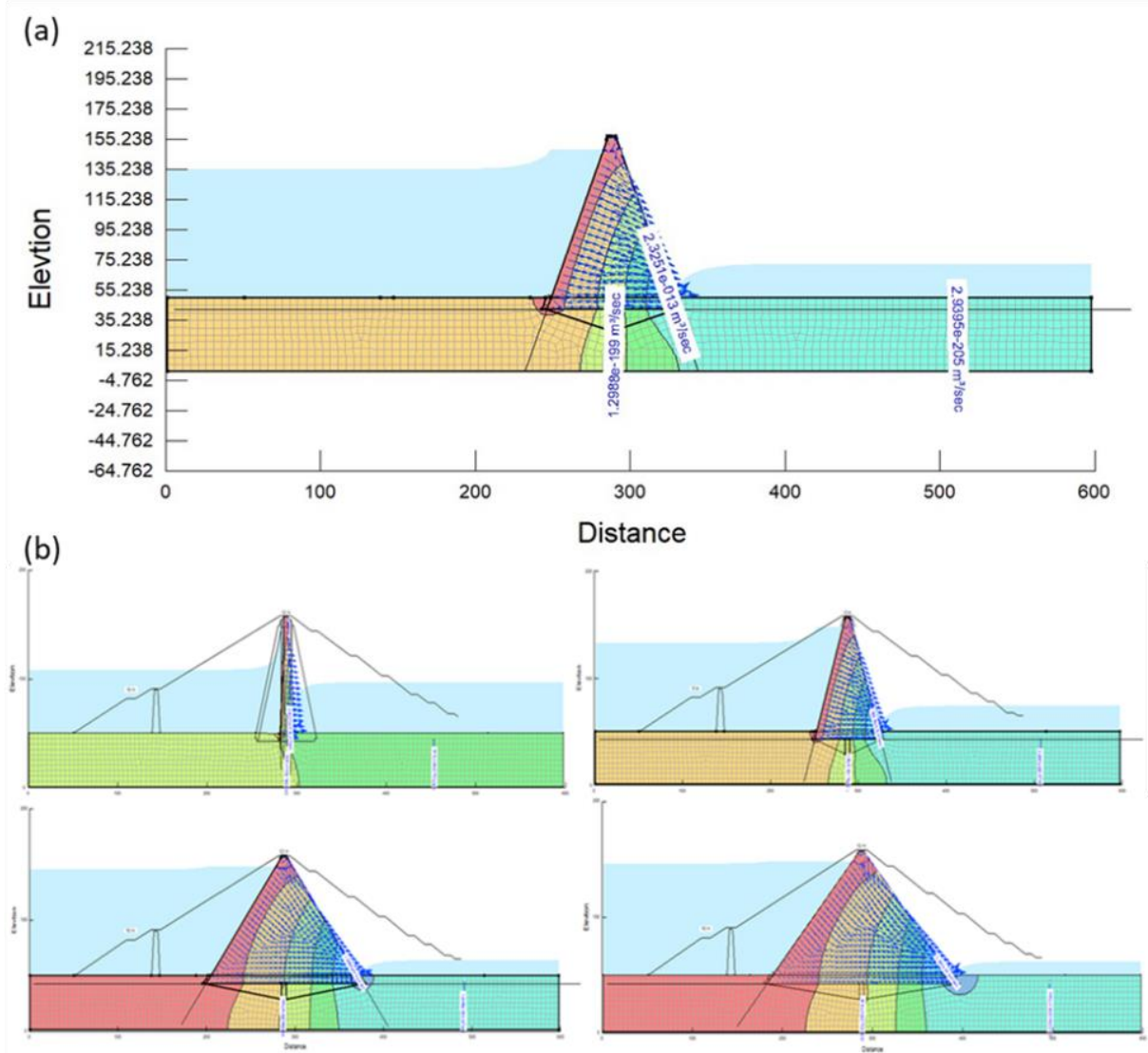

Figure 5. (a): The simulation of Sardash rockfill dam in SEEP/W. (b): illustration of for different simulations with different Sc and clay core 
By analyzing SEEP/W outputs in SPSS, equation (5) is acquired as a semiempirical model. This equation calculates the discharge of seepage in a one-meter width of clay core in a rockfill dam as a function of clay core angle, height, and hydraulic conductivity of clay, while the clay core is considered as an isotropic dam on an unpenetrated foundation. The $\mathrm{R}$ coefficient of this equation is 0.969 , and, in agreement with the residual mean squares, this model has acceptable confidence. More statistic information is provided in Table 5. Moreover, the difference between simulated seepage by SEEP/W and calculated seepage by Equation (5) is illustrated in Figure 6.

$$
q=132.0715 \times k \times h \times \cot S_{C}+6573.221
$$

Table 5. ANOVA Analysis in SPSS for Seepage

\begin{tabular}{llll}
\hline Source & Sum of Squares & df & Mean Squares \\
\hline Regression & 169530373276.645 & 2 & 84765186638.323 \\
Residual & 3007576430.863 & 226 & 13307860.314 \\
Uncorrected Total & 172537949707.508 & 228 & \\
Corrected Total & 96289180791.413 & 227 & \\
\hline
\end{tabular}

Dependent variable: $\mathrm{q}$

a. R squared $=1$ - (Residual Sum of Squares $) /($ Corrected Sum of Squares $)=0.969$
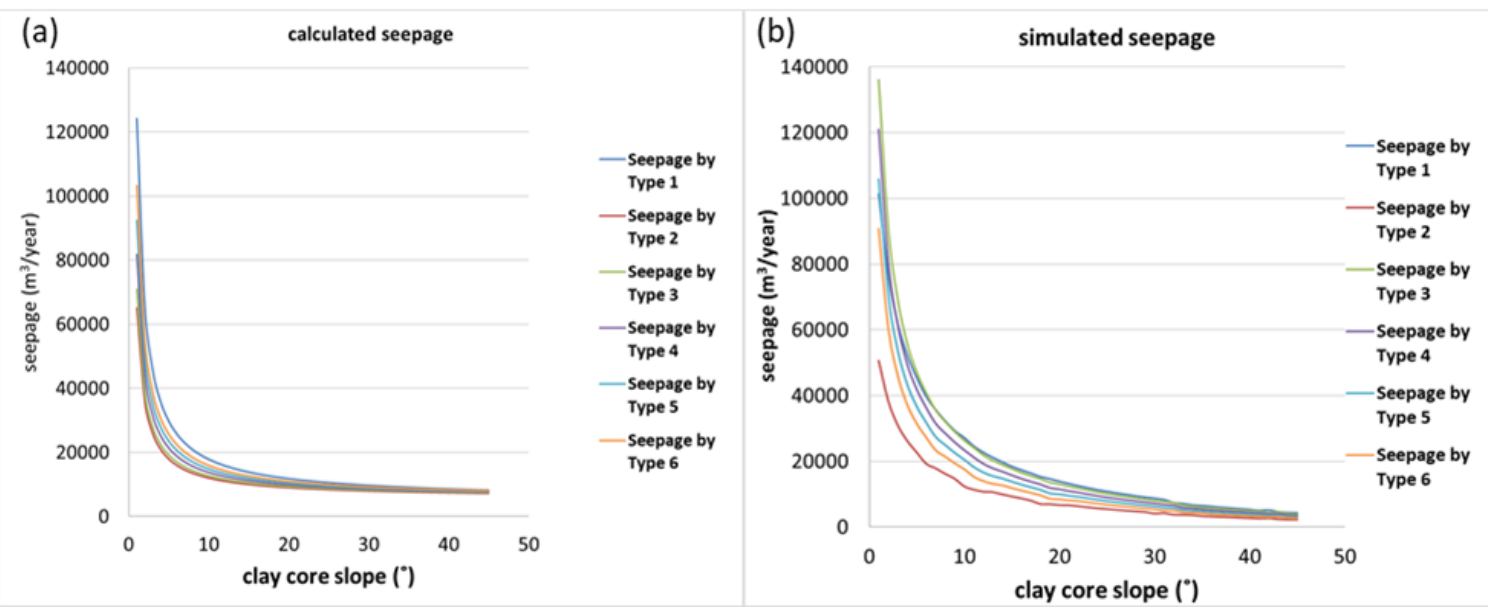

Figure 6. (a): Simulated seepage in SEEP/W for different material in different $\mathrm{S}_{\mathrm{c}}$.

(b): Calculated seepage by Equation (5)

\section{Methodology}

In order to approach the optimal design of the Sardasht rockfill dam, the present study proposes a robust algorithm that takes advantage of two state-of-the-art multi-objective optimization algorithms, including NSGA-III and MOPSO. Likewise, to validate the performance of the proposed algorithm, its outcomes in four MOP are compared with NSGA-III and MOPSO. The described multi-objective optimization algorithms are introduced and explained in this section. 


\section{Multi-Objective Particle Swarm Optimization}

Particle Swarm Optimization (PSO) was presented by Kennedy and Eberhart [19]. This algorithm was inspired by the choreography of a bird flock and was used for singleobjective optimization. Later Coello and Lechuga [20] presented Multi-Objective Particle Swarm Optimization or MOPSO. Their algorithm took advantage of the domination definition and could give a set of non-dominated solutions. In this algorithm, each individual has its place and memory. In each iteration, individuals approach the Pareto front based on their personal best place and the best individual (leader-orientation) place; due to their movements, each individual has a new place, and non-dominated solutions are saved in an archive or repository. If the number of repository members exceeds the defined number, the extra member will be deleted using a gridding method. For more detail, refer to paper [21]. MOPSO flowchart is illustrated in

Figure 7 by blue colour boxes.

\section{Non-dominated Genetic Sorting Algorithm-III}

Srinivas and Deb [22] initially developed the Non-dominated Sorting Genetic Algorithm (NSGA). Exploiting presenting the non-dominated sorting approach method, NSGA was a robust algorithm in its time. In this method, for each solution like $P$, there are two parameters, $S_{p}$ and $n_{p}$, that demonstrate the collection of the population dominated by $P$ and how many times $P$ is dominated by other members, respectively. All members are ranked in different sets (represented by $F$ ) according to their $S_{p}$ and $n_{p}$. The solutions with $n_{p}=0$ are non-dominated and placed in $F 1$. The members with more $n_{p}$ are placed in other sets, like $F 2, F 3, \ldots$

Later, by utilizing the crowding distance definition, NSGA-II was presented by Deb et al. [23]. In this algorithm, between members in the same set, the solutions with a bigger crowding distance go to the next generation. Finally, using the reference point and line strategy, NSGA-III was presented by Deb and Jain [24, 25]. In this state-of-the-art algorithm, each normalized member is associated with a reference point instead of using crowding distance. Between the solutions that have the same set, the best solution is chosen by its distance to the reference line and the number of solutions that associate with a reference line or niche count. By this definition, NSGA-III can secure convergence and diversity of solutions. Detailed explanations for constrained and unconstrained optimization by this algorithm are accessible in [24, 25].

\section{Rubik Cube Reproduction Multi-Objective Particle Swarm Optimization}

This study presents an. MOPSO is one of the most popular MOE due to its fast convergence and short computational load, while even by applying mutation operator, MOPOS converges to the local optimums. It has been reported that the diversity of optimal solutions in MOPOS is highly dependent on the diversity of the initial swarm [8]. Conversely, NSGA-III with a longer computational time provides optimal solutions with more diversity and convergence than MOPSO [24,25]. Accordingly, the proposed algorithm in the current study is an enhanced MOPSO that takes advantage of NSGA-III while benefits from a new reproduction method that can significantly reduce the run time and improve diversity.

Figure 7 illustrates the RCR-MOPSPO flowchart without taking advantage of NSGA-III. It should be noticed that blue boxes illustrate the MOPSO roots of RCRMOPSO, and green boxes show RCR-MOSPO exclusive procedure. Thereby by ignoring the green boxes, Figure 7 displays the MOPSO flowchart. 


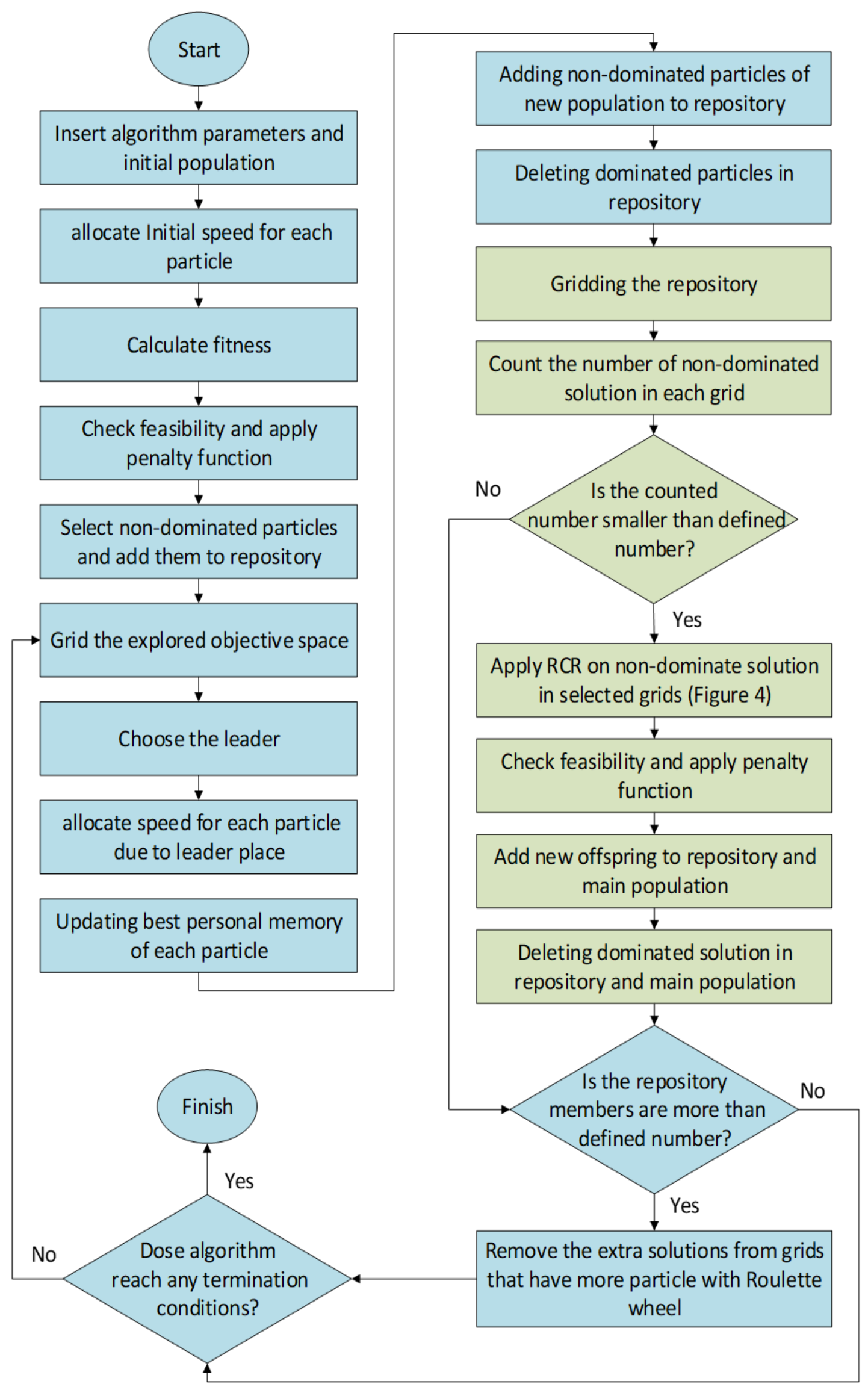

Figure 7: Flow Chart of RCR-MOPSO without enhancing by NSGA-III 
The main difference between this algorithm and the original MOPSO is in Rubik's cubic reproduction (RCR). This one-parent reproducing method was applied to some non-dominated particles in the repository based on their position, considering the number of non-dominated solutions in their neighborhood, as shown in

Figure 7, after a gridding process in the repository, grids that were occupied by several non-dominated solutions (less than a user-predefined number) were chosen for RCR. After RCR, the feasibility and domination of solutions were rechecked, and new feasible, non-dominated solutions remained in the repository. This procedure can improve the diversity and convergence of the algorithm by exploring empty spaces near nondominate solutions or, in other words, explore the undiscovered spaces of the Pareto front. Figure 8 shows this phenomenon when RCR-MOPSO and the original MOPSO, respectively, are applied on MOP2[26] with a population size of 40 after 25 iterations. Red circles in Figure 8(b) specify undiscovered spaces in the MOPSO Pareto front.
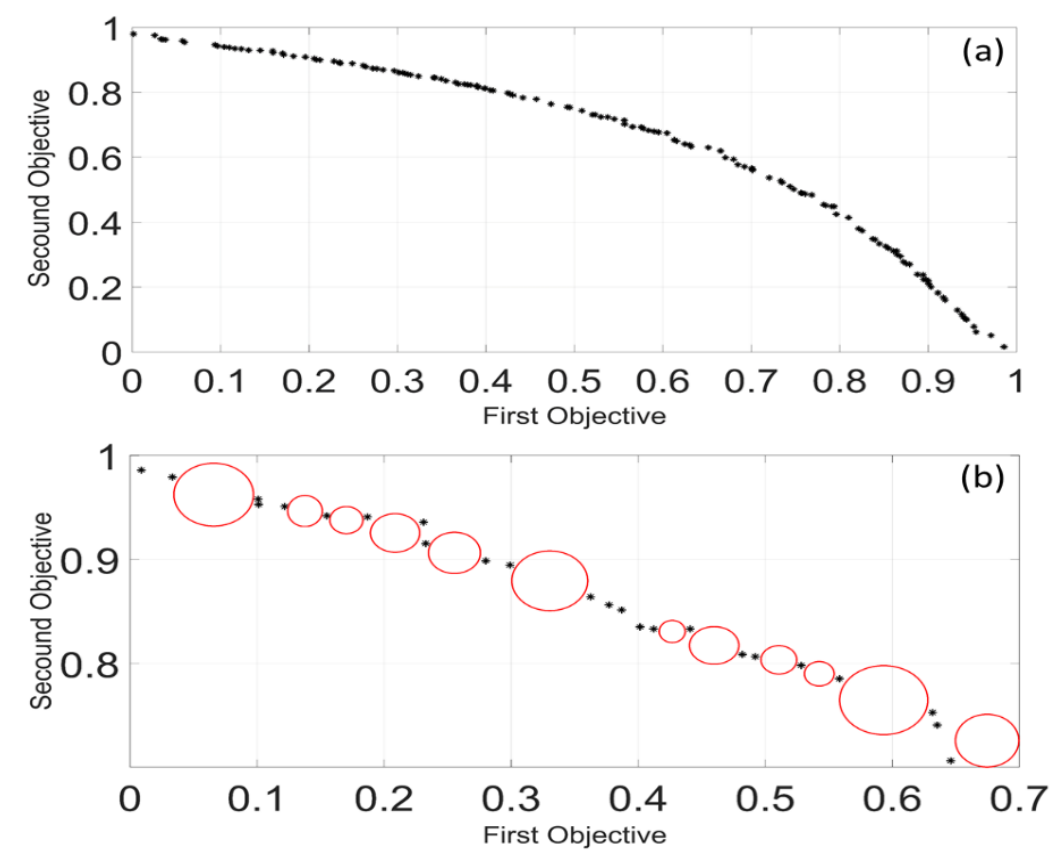

Figure 8: Pareto front of MOP2 after 25 iterations, with an initial population size of 40 solved by (a) RCR-MOPSO (number of non-dominated solutions=143) (b) MOPSO(number of non-dominated solution=24)-(red circles specify undiscovered spaces in MOPSO Pareto front

Concerning Figure 8, RCR-MOPSO approaches a better Pareto front with more diversity and convergence in the same iterations. It is worth noting that the number of nondominated solutions in RCR-MOPSO with the same population size is 143, while it is 24 in MOPSO. Hence, it is expected that RCR-MOPSO reduces the number of iteration and improves MOPSO performance. Later, the RCR and NSGA-III contribution in RCRMOPSO will be discussed.

\section{Rubik Cube Reproduction (RCR)}

As implied by the name, this reproducing method is inspired by the Rubik's cube shape. This method takes one solution in the center of a cube and reproduces more solutions with a different value in apexes and the middle of flanks. Figure 9 shows its function in 2D and 3D, respectively, when there are two and three decision variables in a MOP. 

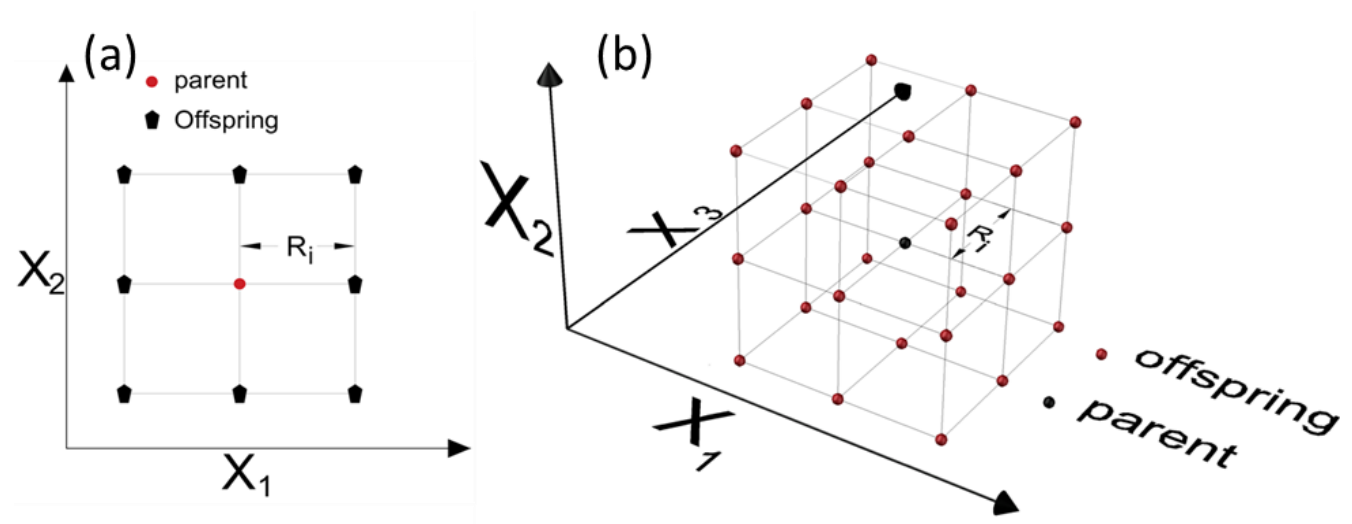

Figure 9: Rubik cubic reproducing in (a): 2D decision variable space when there are two decision variables in MOP (b): 3D decision variable space when there are three decision variables in MOP

If the number of decision variables exceeds three, offspring will form, like a hypercube with the flank length of $2 \mathrm{R}_{\mathrm{i}}$ in each dimension, and this hypercube will surround one parent in its center.

The R shown in Figure 9 represents the distance between offspring and parent. To provide a flexible, vast, and optimal search space, this parameter is considered as the distance between maximum and minimum values of each decision variable in each dimension on the number of populations plus $20 \%$.

$$
R_{i}=\frac{x_{i}^{\max }-x_{i}^{\min }}{n} \times 1.2
$$

where $x_{i}^{\max }$ is the upper bound of the $i^{\text {th }}$ decision variable, $x_{i}^{\text {min }}$ is the lower bound of the $i^{\text {th }}$ decision variable, and $n$ is the population size. Some new solutions could be greater than $x_{i}^{\text {max }}$ or smaller than $x_{i}^{\text {min }}$. In this case, RCR eliminates solutions out of the defined range. The flowchart of RCR is illustrated in Figure 10.

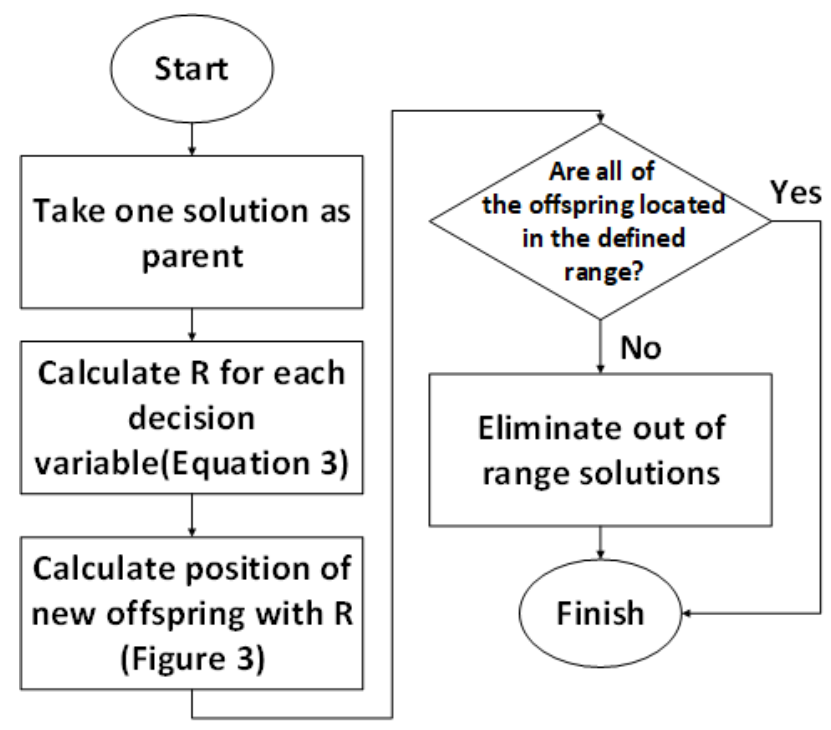

Figure 10: Flowchart of Rubik Cubic Reproducing (RCR) 


\section{Robust MOPSO with NSGA-III}

Both MOPSO and NSGA-III have some advantages and disadvantages. NSGA-III can provide answers with better quality, while MOPSO has a shorter computation time, thus is faster. Considering the advantages of both algorithms, the present study enhances MOPSO by taking advantage of NSGA-III in the initial stage. An ordinary MOPSO starts with a random population, while RCR-MOPSO initially runs NSGA-III with a small population and a limited number of iterations. After Rubik's cube reproduction, the feasibility of solutions is checked using the death penalty. This process eliminates unfeasible solutions. In the next step, MOPSO starts working with a new population that was acquired from a set of non-dominated solutions. Figure 11 displays the comprehensive flowchart of RCRMOPSO enhanced by NSGA-III.

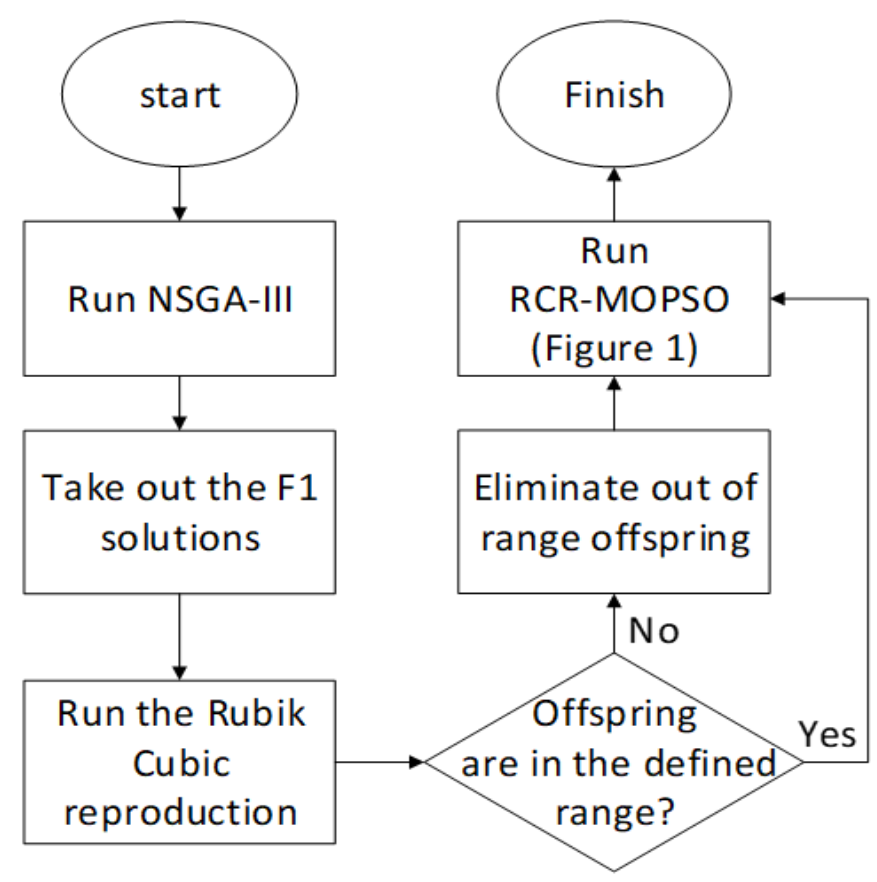

Figure 11: Flowchart Of RCR-MOPSO after enhancing by NSGA-III

\section{Performance Metrics}

The quality of solutions plays a prominent role in any MOP. Performance metrics are used for this goal. The quality of a set of solutions or a front is represented by three parameters, convergence, spread, and distribution. A suitable performance metric should be capable of considering all the mentioned parameters simultaneously. This study takes advantage of two standard performance metrics, IGD and $\mathrm{HV}$, to compare the performance of algorithms. Moreover, to evaluate the componential time of each algorithm, this study considers each algorithm runtime.

\section{Inverted Generational Distance}

Inverted Generational Distance or IGD follows the same calculation as a primary metric called generational distance or GD. IGD evaluates solutions and shows how close they are to the true Pareto front [27]. Simply put, GD is the distance between each objective vector calculated by an optimization algorithm and the closest objective vector in the true Pareto front of the problem [28]. The following equation calculates GD: 


$$
\begin{gathered}
G D(A, T)=\frac{1}{|A|}\left(\sum_{a \in A} \min _{r \in R} d(a, t)^{P}\right)^{1 / P} \\
d(a, t)=\sqrt{\sum_{k=1}^{M}\left(a_{k}-t_{k}\right)^{2}}
\end{gathered}
$$

where $A$ represents the approximation front, $T$ is the true Pareto front, $a$ is an objective vector in $A, t$ is an objective vector in $T$, and the value of $P$ is equal to 2 , later changed to one for more elucidation [29].

Even though GD was a fast metric and had a correlation to convergence, it had a high sensitivity to the size of the approximation front. That means a large size front with poor quality may be ranked highly by GA [27]. In IGD, the input is reversed; in other words, IGD $(a, b)=$ GD (b, a). We can say that IGD is equal to GD, but the distances measured in GD are averaged in IGD. Compared to GD, IGD has low sensitivity to the size of the approximation front and directly matches more closely to convergence, spread, and distribution [29].

\section{Hypervolume Evaluation Index}

Hypervolume Evaluation Index (HV) considers both convergence and diversity and is defined as the volume of space dominated by the searched solution instead of the reference point set [30]. When considering $X$ as a set of non-dominated solutions, the Hypervolume of this set is the total size of the space that is dominated by $X$. If $X$ has greater Hypervolume than $\mathrm{Y}, \mathrm{X}$ is taken to be a better non-dominated set than Y. Detailed information about this metric is accessible in [30]. Most performance metrics like GD and IGD use the true Pareto front. Therefore, in a real-world problem, when there is no knowledge about the true Pareto front, HV is considered the most appropriate metric for this type of problem.

In this study, Hypervolume relative to the true Pareto front for each test problem is calculated and compared with the Pareto front, which each MOEA achieves. Thereupon the result of this comparison is presented as a number between $0 \%$ to $100 \%$. The mentioned method was used in a recent study and provides a more proper perspective on HV [31].

\section{Computational Experiment}

The essential design factors of the Sardasht rockfill dam were defined by Equation (3), (4), and (5). In order to approach the multi-optimal design of this dam, these equations need to be defined as the objective functions of a MOP to be further solved by the proposed algorithm (i.e., RCR-MOPSO). In order to validate the performance of RCR-MOPSO its performance for solving the Sardasht dam shape optimization problem, two standard benchmark MOP and a real-world MOP are compared with the performance of NSGA-III and MOPSO for solving the same problem.

Optimization problems are common in most areas. These problems are classified into single objective and multi-objective optimization problems due to the number of objective functions. Multi-objective problems have two or more objective functions, and these functions mostly contradict each other. Therefore no solution satisfies all objectives; to conquer this conflict, there is a set of feasible solutions [32]. Any multi-objective optimization problem can be represented by following the mathematical model: 


$$
\begin{gathered}
\min y=f(x)=\left[f_{1}(x), f_{2}(x), \ldots, f_{m}(x)\right]^{T} \\
\text { Subject to: } \\
g_{j}(x) \leq \quad(j=1,2, \ldots, z) \\
h_{k}(x)=0 \quad(k=1,2, \ldots, e) \\
x_{i}^{\text {min }} \leq x_{i} \leq x_{i}^{\text {max }} \quad(i=1,2, \ldots, n) \\
X=\left[x_{1}, x_{2}, \ldots, x_{n}\right]^{T} \in \Theta \\
Y=\left[y_{1}, y_{2}, \ldots, y_{n}\right]^{T} \in \Psi
\end{gathered}
$$

where $m$ is the number of optimized objective functions, $\Theta$ is an n-dimensional search space and is determined by the upper bound $X^{\max }=\left[x_{1}^{\max }, x_{2}^{\max }, \ldots, x_{n}^{\max }\right]^{T}$ and lower bound $X^{\text {min }}=\left[x_{1}^{\text {min }}, x_{2}^{\text {min }}, \ldots, x_{n}^{\text {min }}\right]^{T}$ of decision variables $x_{i}(\mathrm{i}=1,2, \ldots, \mathrm{n})$, and $\Psi$ is the m-dimensional vector space of objectives functions and is determined by $\Theta$ and the objective function $f(x)$. Equations $g_{j}(x) \leq 0(\mathrm{j}=1,2, \ldots, \mathrm{p})$ and $h_{k}(x)=0(\mathrm{k}=1,2, \ldots, \mathrm{q})$ represent $z$ inequality constraints and $e$ equality constraints, respectively. Thus, if $p=q=$ 0 , the problem is simplified as an unconstrained multi-objective optimization problem.

\section{The Employed Multi-Objective Optimization Problems}

This section is extended on explaining the Sardasht Rockfill Dam Shape Optimization Problem (termed RSDO), two employed benchmarked MOP (i.e., DTLZ-2 and MOP2), and a real-world MOP (i.e., CSDV).

\section{Rockfill Dam Shape Optimization (RSDO)}

Objective functions: Regarding this study demands three following functions considered as objective functions in the rockfill dam shape optimization. Equation (9) defines the first objective, which is the minimum seepage through the clay core for different clay core angles according to Equation (5). Equation (10) represents the maximum FOS in the downstream slope of the rockfill dam for different clay core and downstream crust angles, which is obtained based on equation (4). Equation (11) is the minimum construction cost in the biggest cross-section of the Sardasht rockfill dam for different clay core and downstream crust angles based on Equation (3).

$$
\min \left[q_{n}\left(S_{C}\right)\right] \leftrightarrow \min \left(132.0715 \times k \times h \times \cot S_{C}+6573.221\right)
$$

$$
\begin{aligned}
\max \left[\operatorname{FOS}_{n}\left(S_{C}, S_{D c}\right)\right] & \\
& \leftrightarrow \max \left(-0.374 \times\left(\tan S_{C} \times \tan \varphi_{C}\right)+7.428 \times \frac{C_{C}}{\gamma_{C} \times H_{C}}\right. \\
& \left.+0.439 \times\left(\tan S_{D c} \times \tan \varphi_{C r}\right)+7.964 \times \frac{C_{C r}}{\gamma_{C r} \times H}+0.866\right)
\end{aligned}
$$

$$
\begin{aligned}
\min \left[P_{n}\left(S_{C}, S_{D c}\right)\right] & \\
& \leftrightarrow \min \left(P_{C}\left(H_{C}^{2} \times\left(\tan S_{C}+\frac{d_{c}}{H_{c}}\right)\right)\right. \\
& +\left(P_{C r}\left(\frac{H_{C r}^{2}}{2} \times\left(\tan S_{U c}+\tan S_{D c}+2 \times \frac{d_{C r}}{H_{C r}}\right)-A_{1}\right)\right)
\end{aligned}
$$


Decision variable: According to the defined objective functions, there are two decision variables in the proposed optimization problem, including $\mathrm{S}_{\mathrm{C}}$ and $\mathrm{S}_{\mathrm{Dc}}$. In a rockfill dam, the clay core angle (i.e., $S_{C}$ ) should always be smaller than the crust angle (i.e., $S_{D c}$ ). Moreover, to provide more feasible solutions, these variables are also defined in the acceptable range as follows:

$$
\begin{gathered}
1^{\circ}<S_{C}<45^{\circ} \\
25^{\circ}<S_{D c}<80^{\circ} \\
S_{C}<S_{D c}
\end{gathered}
$$

Constraints: Regarding the acceptable amount of seepage, FOS, and construction cost, there are three constraints in objective space as follows:

1- The amount of seepage is always greater than zero and should be smaller than the original design, which is 9000 cubic meters per year

$$
0<q\left(S_{C}\right) \leq 9000
$$

2- $\quad P$ is always greater than zero and should be smaller than the original design, which is 404585 units.

$$
0<P\left(S_{C}, S_{D c}\right) \leq 404585
$$

3- According to studies by the United States Army, FOS downstream of an embankment dam during a steady-state flow should be greater than 1.5 [18].

$$
\operatorname{FOS}\left(S_{C}, S_{D c}\right)>1.5
$$

\section{Crash Safety Design of Vehicles (CSDV)}

CSDV is a real-world optimization problem presented by Liao et al. [33] for designing vehicle crashworthiness. CSDV considers the thickness of five reinforced members around the frontal structure as objective functions. Consequently, acceleration characteristics and toe-board intrusion are used as objective functions. These objectives are represented in Equation(16) by $f_{1}, f_{2}$ and $f_{3}$, receptively.

$$
\begin{gathered}
\min f_{1}(X)=1640.283+2.3573255 x_{1}+2.3220035 x_{2}+4.5688768 x_{3} \\
+7.7213633 x_{4}+4.4559504 x_{5} \\
\min f_{2}(X)=6.5856+1.15 x_{1}-1.0427 x_{2}+0.9738 x_{3}+0.8364 x_{4}-0.3695 x_{1} x_{4} \\
+0.0861 x_{1} x_{5}+0.3628 x_{2} x_{4}-0.1106 x_{1}{ }^{2}-0.3437 x_{3}{ }^{2}+0.1764 x_{4}{ }^{2} \\
\min f_{3}(X)=-0.0551+0.0181 x_{1}+0.1024 x_{2}+0.0421 x_{3}-0.0073 x_{1} x_{2}+0.024 x_{2} x_{3} \\
-0.0118 x_{2} x_{4}-0.0204 x_{3} x_{4}-0.008 x_{4} x_{3}-0.0241 x_{2}{ }^{2}+0.0109 x_{4}{ }^{2}
\end{gathered}
$$




$$
X=\left[x_{1}, x_{2}, x_{3}, x_{4}, x_{5}\right], \quad 1 m m \leq X \leq 3 m m
$$

This real-world problem was extracted by a non-linear regression from a series of experimental results. Due to the similarity of this method with the method used in the Sardasht shape optimization problem, the present study exploits CSDV to provide a better perspective.

\section{Deb Thiele Laumanns Zitzler problem (DTLZ)}

Deb et al. [34] masterminded this generic sphere test problem. DTLZ2 is scalable in decision variable and objective size and can be expressed by the following equation:

$$
\begin{gathered}
\min f_{1}(x)=\left(1+g\left(X_{M}\right)\right) \cos \left(x_{1} \pi / 2\right) \ldots \cos \left(x_{M-2} \pi / 2\right) \cos \left(x_{M-1} \pi / 2\right) \\
\min f_{2}(x)=\left(1+g\left(X_{M}\right)\right) \cos \left(x_{1} \pi / 2\right) \ldots \cos \left(x_{M-2} \pi / 2\right) \sin \left(x_{M-1} \pi / 2\right) \\
\min f_{3}(x)=\left(1+g\left(X_{M}\right)\right) \cos \left(x_{1} \pi / 2\right) \ldots \sin \left(x_{M-2} \pi / 2\right) \\
\vdots \\
\min f_{M}(x)=\left(1+g\left(X_{M}\right)\right) \sin \left(x_{1} \pi / 2\right) \\
\text { With } g\left(X_{M}\right)=\sum_{x_{i} \in X_{M}}\left(x_{i}-0.5\right)^{2} \\
0 \leq x_{i} \leq 1 \text { for } i=1,2, \ldots, n
\end{gathered}
$$

Where $M$ is the number of objectives and $x_{i}$ represents the $i$ th decision variable. The true Pareto-optimal solution needs to satisfy $\sum_{m=1}^{M} f_{m}{ }^{2}=1$. Therefore, three objective Pareto-optimal solutions lie inside the first octant of the unit sphere.

Jian and Deb [24] presented constrained DTLZ2 and called it C2-DTLZ2. In this constraint problem, some part of theDTLZ2 Pareto-optimal front is infeasible. In the C2DTLZ2 problem, only the regions of objective space that lie inside each of the $M+1$ hyperspheres of radius $r$ are made feasible. These constraints could be calculated by Equation(18)(17). The Pareto-optimal front of C2-DTLZ2 and DTLZ2 are illustrated in Figure 12.

$$
\begin{aligned}
C(x)=-\min & \left\{\operatorname { m i n } _ { i = 1 } ^ { M } \left[\left(f_{i}(X)-1\right)^{2}\right.\right. \\
& \left.\left.+\sum_{j=1, j \neq i}^{M} f_{j}^{2}-r^{2}\right],\left[\sum_{i=1}^{M}\left(f_{i}(x)-1 / \sqrt{M}\right)^{2}-r^{2}\right]\right\} \geq 0
\end{aligned}
$$
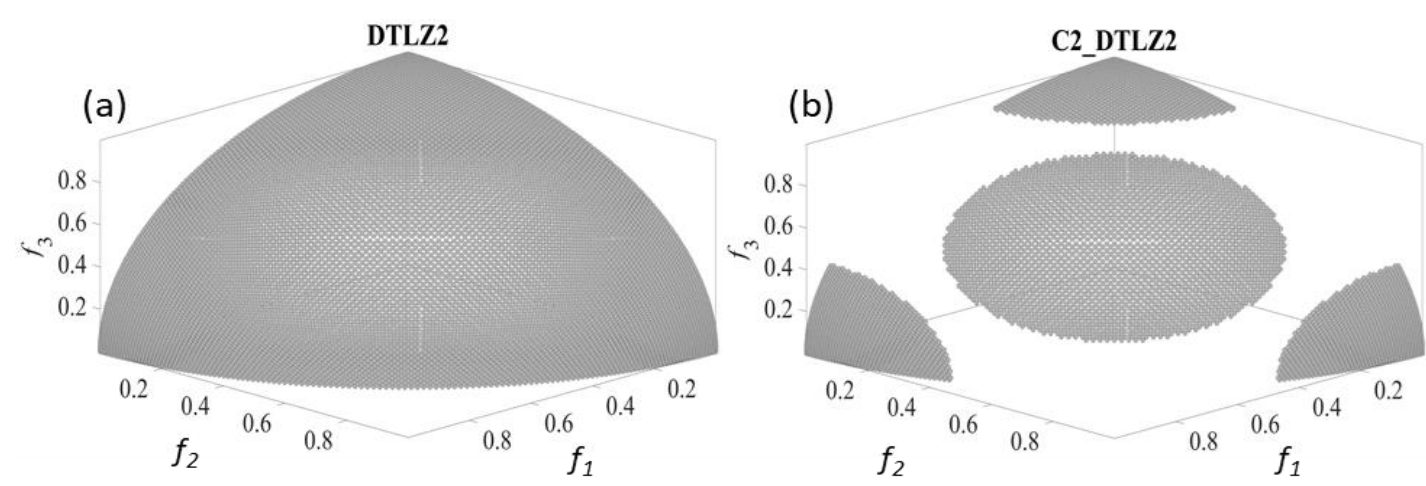

Figure 12. the true Pareto front of (a): DTLZ2 (b): C2-DTLZ2 


\section{Test Multi-Objective Problem Two (MOP2)}

MOP2 is a simple test function that consists of two single-objective functions. MOP2 is scalable in decision variable size and is expressed by the following equations:

$$
\begin{aligned}
\min f_{1}(x) & =1-\exp \left(-\sum_{i=1}^{n}\left(x_{i}-\frac{1}{\sqrt{n}}\right)^{2}\right. \\
\min f_{1}(x) & =1-\exp \left(-\sum_{i=1}^{n}\left(x_{i}+\frac{1}{\sqrt{n}}\right)^{2}\right. \\
-4 & \leq x_{i} \leq 4 \quad i=1,2, \ldots, n
\end{aligned}
$$

The minimum solutions for $f_{1}(x)$ and $f_{2}(x)$ are in $x_{i}^{*}=-1 / \sqrt{n}$ and $x_{i}^{*}=1 / \sqrt{n}$, respectively. Therefore, the Pareto-optimal set is constituted with all solutions in $x_{i}^{*} \in$ $[-1 / \sqrt{n}, 1 / \sqrt{n}]$. More information is provided in [26].

The present study adopted PlatEMO [35] as a novel MATLAB open-source platform for evolutionary multi-objective optimization to run MOE. This platform not only presents a huge number of established MOEAs but also provides a suitable ground for developing new MOEAs. Lately, this platform has become a popular tool among scholars for handling MOPs. Many researchers have adopted PlatEMO for solving MOPs in different areas (e.g.,[36], [37], [38], [39], [40], [41]).

Parametrizations of employed multi-objective optimization algorithms and the proposed algorithm are illustrated in Table 6.

Table 6. Parametrizations of the NSGA-III, MOPSO, and RCR-MOPSO

\begin{tabular}{llll}
\hline Algorithm & Parameter & Value & Parameter description \\
\hline NSGA-III & Maxit & 1000 & Maximum Number of Iterations \\
& nDiv & 10 & $\begin{array}{l}\text { Number of divisions which is used in } \\
\text { generating reference points }\end{array}$ \\
& nPop & 100 & Population Size \\
& pCross & 0.5 & Crossover Percentage \\
& pMut & 0.5 & Mutation Percentage \\
MOPSO & $\mu$ & 0.02 & Mutation Rate \\
& Maxit & 1000 & Maximum Number of Iterations \\
& nPop & 100 & Population Size \\
& nRep & 100 & Repository Size \\
& w & 0.5 & Intertie Weight \\
& wdamp & 0.99 & Intertie Weight Damping Rate \\
& PLC & 1 & Personal Learning Coefficient \\
& GLC & 1 & Global Learning Coefficient \\
& nGrid & 5 & Number of Grids per Dimension \\
& $\alpha$ & 0.1 & Inflation Rate \\
& $\beta$ & 2 & Leader Selection Pressure \\
& $\Upsilon$ & 2 & Deletion Selection Pressure \\
& $\mu$ & 0.1 & Mutation Rate \\
RCR- & $R_{i}$ & Equation (6) & distance between offspring and parent \\
& & & Allowed number of non-dominated \\
& pGrid & 4 & solutions in each grid \\
\hline
\end{tabular}

* all of MOPSO parameters are used in RCR-MOPSO 
The number of random seeds for all problems is 100; moreover, functions are evaluated 10000 times to guaranty the convergence of each MOE, despite MOE showing a stable performance after 1000 iterations.

It is also should be noticed that the present experiment is running on a PC with a Core i5 CPU at $2.50 \mathrm{GHz}$ and $8 \mathrm{~GB}$ of RAM.

\section{Results and discussion}

The present study's results could be divided into two categories. At first, the performance of RCR-MOPSO in comparison with NSGA-III and MOPSO in four MOPs is investigated. After the performance of RCR-MOPSO is validated, the proposed optimal solutions in the Sardasht rockfill dam are proposed.

\section{Algorithm Results}

To strengthen perception about RCR-MOPSO and shape optimization problem, RCR-MOPSO compared with two original algorithms, MOPSO and NSGAIII, in five employed MOPs (i.e., MOP2, DTLZ2, C2-DTLZ2, CSDV, RDSO). Thereby, after 30 runs, the Hypervolume analyses, IGD comparison, and Runtime comparison are illustrated in Figure 13, Figure 14, and Figure 15, respectively.
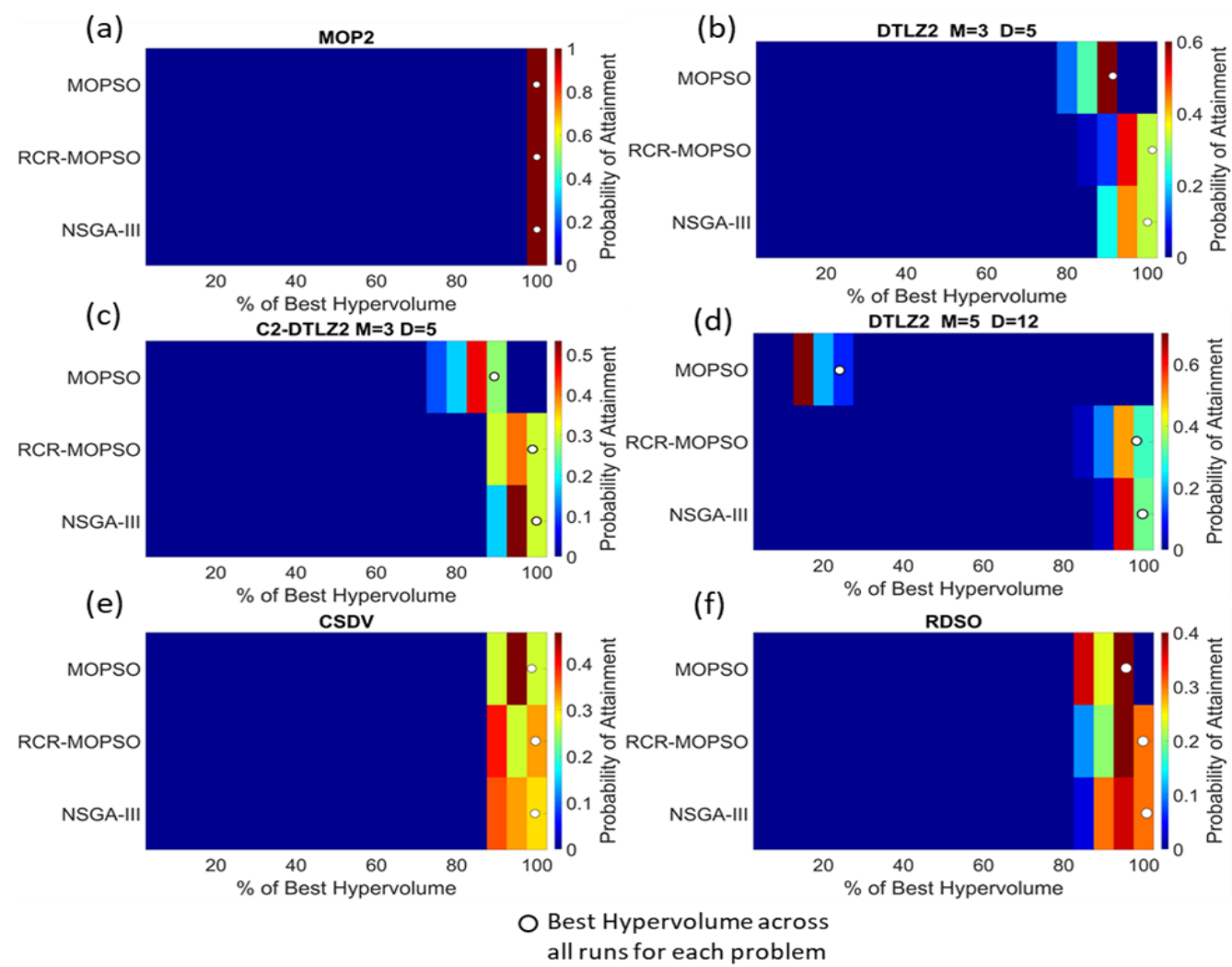

Figure 13. Best single run and probability of Hypervolume attainment of 30 times run in (a):

MOP2 (b): DTZL2 with three objective functions and five decision variables, (c): C2-

DTLZ2 with three objective functions five decision variables (d): DTLZ2 with five objective functions and twelve decision variables (e): CSDV (f): RSDO. The vertical axis shows the

percentage of the best Hypervolume, and the color scale represents the probability of attaining a given level of performance. It should be noticed that each problem has its own color scale. Moreover, the Best observed performance of each MOEA for each MOPs is shown by a white dote. 


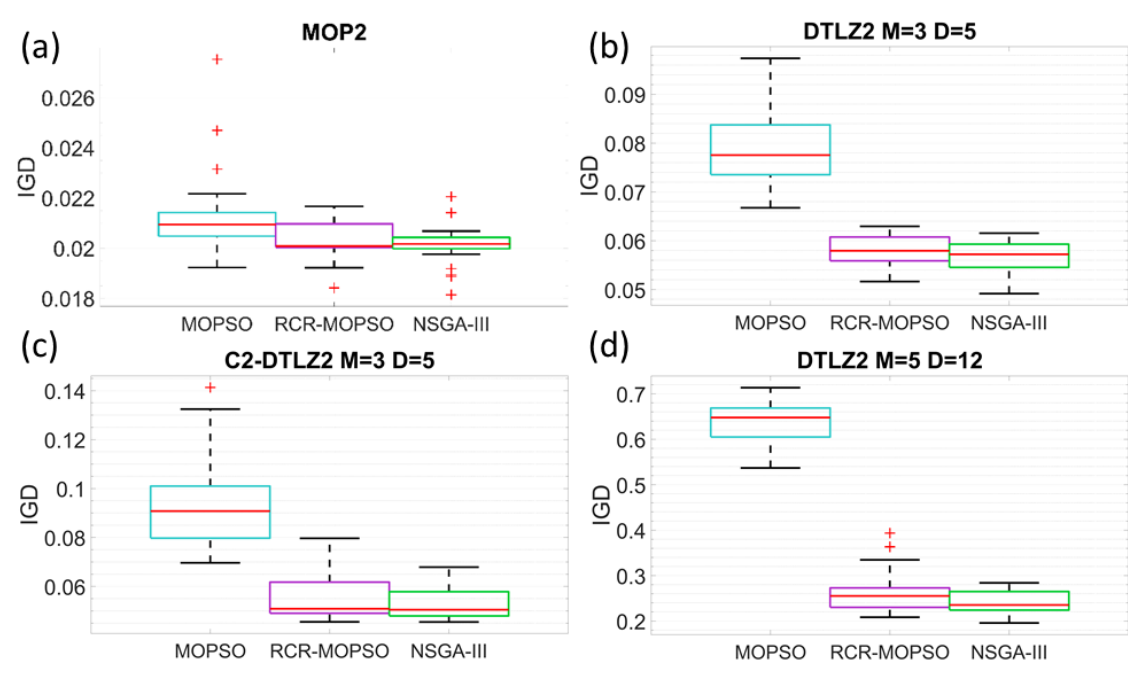

Figure 14. IGD comparison for each MOEAs in 30 times run in (a): MOP2 (b): DTZL2 with three objective functions and five decision variables, (c): C2-DTLZ2 with three objective functions five decision variables (d): DTLZ2 with five objective functions and twelve decision variables. The vertical axis represents the IGD calculated by Equation(7). The red cross represents the outliner IGD in each MOEA. The Red line inside of each box represents the average IGD in each MOEA
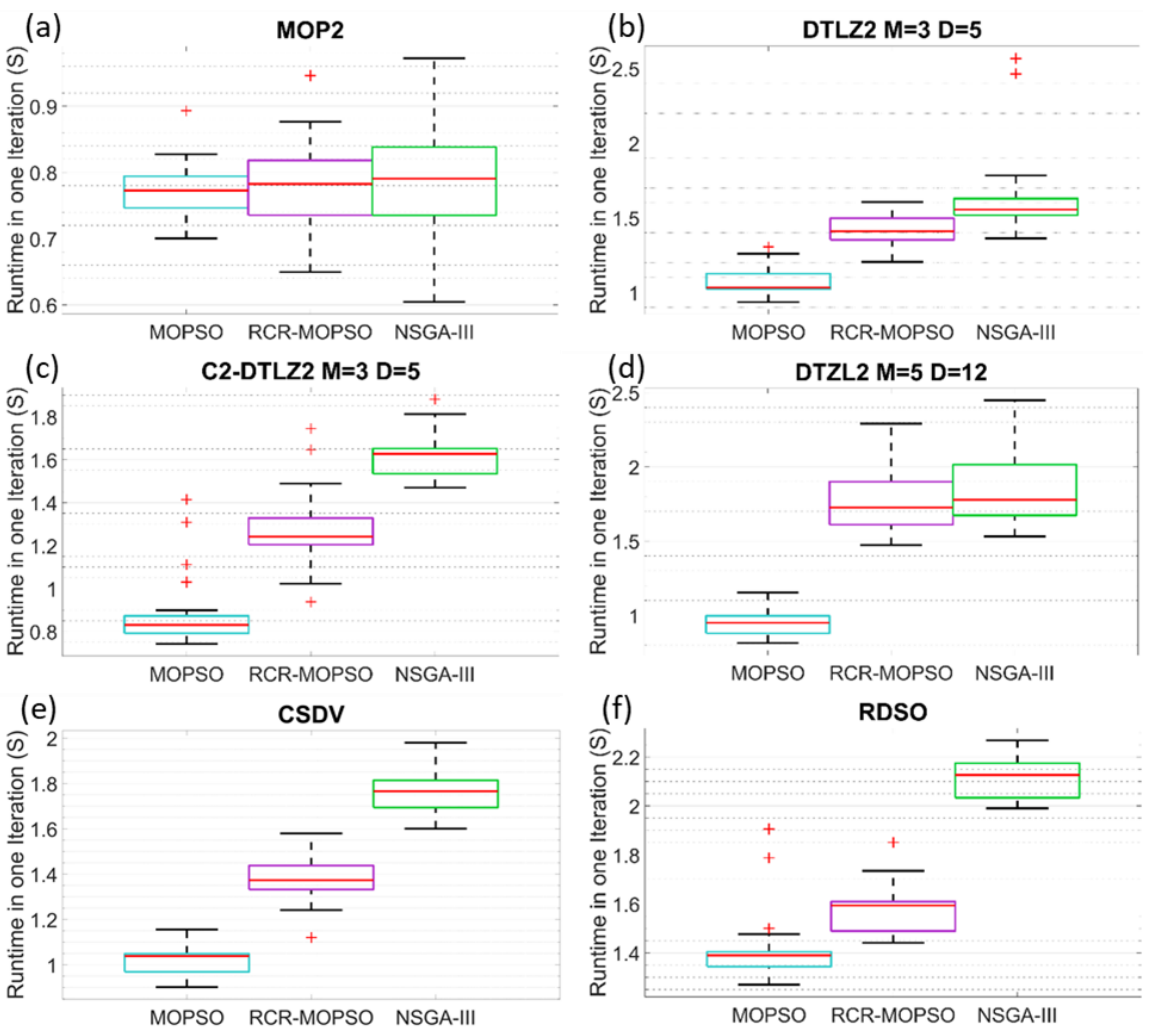

Figure 15. Runtime comparison for each MOEAs in 30 times run in (a): MOP2 (b): DTZL2 with three objective functions and five decision variables, (c): C2-DTLZ2 with three objective functions five decision variables (d): DTLZ2 with five objective functions and twelve decision variables. The vertical axis represents the Runtime of each MOE in one iteration. The red cross represents the outliner Runtime in each MOEA. The Red line inside of each box represents the average runtime in each MOEA 
Concerning Figure 13(a), all three MOEAs in MOP2, as a simple unconstraint MOP, showed a perfect performance in HV when all of them achieved $100 \%$ of analytical Hypervolume. The same behavior is observable in Figure 14(a) when for MOP2, all MOEAs show a very small IGD (i.e., between 0.019 and 0.022 ). Figure 15 shows the average runtime in each MOEAs for one iteration for each MOP. According to Figure 15(a), all MOEAs have solved MOP2 in a brief time (i.e., 0.7 seconds on average) and the maximum runtime (close to one second) observed in NSGA-III.

Figure 13(b), Figure 14(b), and Figure 15(b) are illustrating HV, IGD, and runtime for DTLZ2, respectively. It should be noticed that in these figures, DTLZ2 has three objective functions and five decision variables. Concerning Figure 13(b), MOPSO could not archive $90 \%$ to $100 \%$ of true Pareto front Hypervolume. In NSGA-III and RCR-MOPSO, these two algorithms attained $95 \%$ to $100 \%$ of true Pareto Hypervolume with a probability of 0.3 . Moreover, RCR-MOPSO, in its best performance, approached $97 \%$ of true Pareto Hypervolume; this variable for NSGA-III was observed in $95.3 \%$. Furthermore, the IGD comparison for DTLZ2 is in agreement with its HV. According to Figure 14(b), RCRMOPSO and NSGA-III showed 49\% smaller IGD than MOPSP. The difference between average IGD in NSGA-III and RCR-MOPSO is negligible. The average runtime in Figure 15(b) shows the supremacy of MOPSO on RCR-MOPSO and the superiority of RCRMOPSO. It should be noticed that RCR-MOPSO is 0.2 seconds faster than NSGA-III on average, which means RCR-MOPSO is 20 seconds faster than NSGA-II in 100 iterations for DTZL2.

The performance of MOEAs on C2-DTLZ2 is shown in Figure 13(c), Figure 14(c), and Figure 15(c). The same behavior was perceived in DTLZ2 is perceptible in C2-DTLZ2 as a constrained benchmark. RCR-MOPSO comes slightly after NSGA-III in HV when both algorithms show an equal probability in $95 \%$ to $100 \%$, and NSGA-III shows a higher probability in the range of $90 \%$ to $95 \%$. In terms of IGD, according to Figure 14(c), NSGAIII and RCR-MOPSO showed similar performance, and both of them are 35\% smaller than MOPSO. Concerning Figure 15(c), MOPSO submitted the shortest runtime (i.e., 0.88 second on average). Here RCR-MOPSO, by submitting 1.38 seconds runtime on average, is 0.4 seconds faster than NSGA-III in each iteration.

Figure 13(d), Figure 14(d), and Figure 15(d) illustrate the performance of all MOEAs in DTLZ2. It should be noticed that here DTZL2 has five objective functions and twelve decision variables. With increasing decision variables and objective functions in DTLZ2, NSGA-III surpasses RCR-MOPSO. As illustrated in Figure 13(d), the probability of attaining $95 \%$ to $100 \%$ of true Pareto Hypervolume is 0.28 in NSGA-III and 0.23 in RCR-MOPSO. Furthermore, the best-observed Hypervolume across all runs is $96 \%$ and 98.2\% for RCR-MOPSO and NSGA-III, respectively. Respecting Figure 15(d), MOPSO showed shorter runtime. Besides, the difference between RCR-MOPSO and NSGA-III average runtime is negligible (0.05 second). RCR-MOPSO higher runtime this MOP was caused by the Rubik's cubic reproduction sensitivity to the number of decision variables. In this reproducing method, with more decision variables, the number of new populations increases with a geometric progression. Thereby this enormous population leads RCRMOPSO to a higher runtime.

CSDV and RDSO are real-world problems. Hence there is not any known true Pareto front for these two MOPs. Consequently, the IGD metric cannot be calculated for CSDV and RSDO. Moreover, the set with solutions non-dominated across all Pareto fronts from all runs with all algorithms for each problem is considered as the best possible Pareto front. Hence the probability of attainment for CSDV and RDSO calculates by the best possible Pareto front. 
Figure 13(e) and Figure 14Figure 15(e) show HV and runtime of CSDV, respectively. MOPSO attained $95 \%$ to $100 \%$ of best Hypervolume by the probability of 0.21 , this parameter for NSGA-III and RCR-MOPSO are 0.29 and 0.32 , respectively. Moreover, the difference between the best Hypervolume in NSGA-III and RCR-MOPSO is negligible. Concerning Figure 15(e), MOPSO submitted the fastest runtime. Further, RCRMOPSO appeared to be 0.38 seconds faster than NSGA-III in this problem.

Lastly, the MOEAs performances in RDSO are shown in Figure 13(f) and Figure 14Figure 15(f). According to Figure 13(f), MOPSO could not find any solution in $95 \%$ to $100 \%$ of the best Hypervolume. Alternatively, both RCR-MOPSO and NSGA-III attained the same range by the probability of 0.3 . Moreover, across all runs, NSGA-III achieved the best Hypervolume in $96 \%$, and it is just $1.2 \%$ higher than RCR-MOPSO. Concerning Figure 15(f), MOPSO submitted the fastest runtime, and RCR-MOPSO submitted a runtime 0.5 second faster than NSGA-III in RDSO, which means that in 100 iterations, RCR-MOPSO is 50 seconds faster than NSGA-III.

Comprehensively, RCR-MOPSO performance compared to MOPSO significantly improved. RCR-MOPSO showed a reliable performance, similar to NSGA-III. Moreover, on average, the run time in RCR-MOPSO was decreased by 0.38 seconds for each iteration compared to NSGA-III. Thereby, RCR-MOPSO is suggested for researchers and practitioners with limited computing resources.

\section{Shape Optimization Results}

The last section pivots around RCR-MOPSO reliability. Regarding the acceptable performance of this algorithm, RCR-MOPSO is applied on RDSO and results in a set of feasible and non-dominated solutions extracted as final results. The summary of these results is shown in Table 7. By virtue of this table, it is evident that the final results covered all ranges of decision variables. Solutions pervade between the maximum and minimum amount for each decision variable.

Moreover, the solutions satisfied all the constraints and reduced the construction cost by $31.12 \%$ on average compared to the original design price. Besides, seepage and safety factor respectively improved by $15.84 \%$ and $27.78 \%$ on average. Notice that the minimum number of results is equal to the number of random seeds, which means there are at least 100 answers that cannot dominate each other.

Table 7: Final Result of RCR-MOPSO on RDSO

\begin{tabular}{llllll}
\hline & clay core angle & Crust shell angle & seepage & FOS & $\begin{array}{l}\text { price of } \\
\text { construction }\end{array}$ \\
\hline Average & 12.077 & 72.868 & 7574.149 & 2.328 & 278165.38 \\
maximum & 44.617 & 80.00 & 8999.1 & 2.983 & 390453.28 \\
minimum & 3.116 & 51.451 & 6707.066 & 1.501 & 159324.25 \\
Standard deviation & 9.04 & 7.502 & 638.876 & 0.442 & 57392.8 \\
\hline
\end{tabular}

By considering all the results and mentioned issues in this study, the Sardasht rockfill dam could be optimized to have a higher safety factor, less seepage, and a lower construction cost. Regarding the consideration for this problem, all of the solutions dominated the original design. The presented equations for FOS and seepage can be used for another similar rockfill dam. 


\section{Conclusions}

The present study optimized the shape of a rockfill dam by considering clay core angle and crust shell angle as decision variables. FOS, seepage, and construction cost were taken as objective functions to approach the optimal design. To calculate seepage and FOS, the Sardasht rockfill dam was simulated using SEEP/W and SLOP/W. These simulations were repeated with different angles of clay core and crust shell.

Regarding simulation results, two numerical models were presented for FOS and seepage. According to the non-linear regression results, the presented semi-empirical models showed acceptable confidence and could be used for similar rockfill dams with the same range of physical parameters. To approach the optimal design, this study took advantage of a robust particle swarm optimization. The algorithm results were compared with NSGA-III and MOPSO. According to the final optimization results, RCR-MOPSO has consistent performance. Despite some benchmark problems with more decision variables, performance metrics were slightly better in NSGA-III; the improved run time in RCR-MOPSO makes it a fast and reliable algorithm. Therefore, Rubik's Cubic reproducing is an acceptable reproducing method based on decision space that can improve elitism and provide more diversity and convergence by searching the empty places near the Pareto front. As RCR is only dependent on the number of decision variables, the number of objective functions does not affect algorithm speed. Hence this algorithm is suggested for problems with a large number of objective functions and few decision variables; however, with applying constraints and the death penalty in the elimination stage, run time can be improved. Numerical models extracted for seepage and FOS have acceptable results and can be used for other similar projects.

Regarding the defined constraints of the problem, all of the solutions dominate the original design, which means all the solutions have more significant FOS and smaller seepage and construction cost. Hence, considering similar plans as a MOP can help engineers access a set of non-dominated solutions with minimum seepage, minimum construction cost, and maximum FOS. This set of solutions provides a better perspective for the designers.

In the case of The Sardasht rockfill dam, according to RCR-MOPSO results, the original plan could be optimized. On average, the construction cost can be improved by $31.12 \%$. FOS and seepage can be improved by $27.78 \%$ and $15.84 \%$, respectively, on average.

Future studies can be performed for improving RCR or can apply RCR-MOPSO to optimize other similar problems. Also, RCR can be applied to another popular algorithm. This algorithm can also be used for other optimization solutions with a small number of decision variables.

\section{References}

[1] B. Chopard, and M. Tomassini, "Particle swarm optimization," In An Introduction to Metaheuristics for Optimization, G. Rozenberg, Th. Bäck, A.E. Eiben, J.N. Kok, and H.P. Spaink, eds.: Springer, Cham, Switzerland. pp. 97-102, 2018. doi:10.1007/9783-319-93073-2_6.

[2] S. Safari, T. Hajilounezhad, and M. Aliehyaei, "Multi-objective optimization of solid oxide fuel cell/GT combined heat and power system: A comparison between Particle Swarm and Genetic Algorithms." International Journal of Energy Research, Vol. 44, No.11, pp. 9001-9020, 2020. doi: 10.1002/er.5610.

[3] A. Mahmoud, X. Yuan, T. Hajilounezhad, and Y. Yuan, "Investigation on labyrinth 
spillway multi-objective optimization with an emphasis on predicting discharge boefficient through different artificial neural networks," Measurement, Vol. 174, pp, 109036, 2021. doi:10.1016/j.measurement.2021.109036.

[4] A. Mahmoud, X. Yuan, M. Kheimi, M.A. Almadani, and T. Hajilounezhad, "An improved multi-objective particle swarm optimization with TOPSIS and fuzzy logic for optimizing trapezoidal labyrinth weir," IEEE Access, Vol. 9, pp. 25458-25472, 2021. doi:10.1109/ACCESS.2021.3057385.

[5] C. Chen, Y. Yuan, and X. Yuan, "An improved NSGA-III algorithm for reservoir flood control operation," Water Resource Management, Vol. 31, No. 14, pp. 44694483, 2017. doi:10.1007/s11269-017-1759-6.

[6] B. Ji, X. Yuan, and Y. Yuan, "Modified NSGA-II for solving continuous berth allocation problem: Using multi-objective constraint-handling strategy," IEEE Transactions on Cybernetics, Vol. 47, No. 9, pp. 2885-2895, 2017. doi:10.1109/TCYB.2017.2669334.

[7] M. Curtis, and A. Lewis, "Reduction of computational load for MOPSO," Paper presented at ICCS 2015 International Conference On Computational Science, 2015, doi:10.1016/J.PROCS.2015.05.435.

[8] A. Pan, L. Wang, W. Guo, and Q. Wu, "A diversity enhanced multi-objective particle swarm optimization," Information Sciences, Vol. 436-437, pp. 441-465, 2018. doi:10.1016/J.INS.2018.01.038.

[9] Y.Q. Xu, K. Unami, and T. Kawachi, "Optimal hydraulic design of earth dam cross section using saturated-unsaturated seepage flow model," Advances in Water Resources, Vol. 26, No. 1, pp. 1-7, 2003. doi:10.1016/S0309-1708(02)00124-0.

[10] X. Cai, Y.L. Wu, J.G. Yi, and Y. Ming. "Research on shape optimization of CSG dams," Water Science and Engineering, Vol. 4, No. 4, pp. 445-454, 2011. doi:10.3882/j.issn.1674-2370.2011.04.008.

[11] S. Haghighatandish, K. Ghaderi, M. Mohammadi, and G. Barani, "Optimization of earth dam dimensions with shuffled complex evolution," Iran Water Resource, Vol. 9, pp. 19-26, 2015.

[12] M. Mohammadi, G.A. Barani, K. Ghaderi, and S. Haghighatandish, "Optimization of earth dams clay core dimensions using evolutionary algorithms," European Journal of Experimental Biology, Vol. 3, No. 3, pp. 350-361, 2013.

[13] M. Montaseri, A Deiminiat, and A. Ghezelsofloo, "Optimization of clay core dimensions in earth dams using genetic algorithm," Journal of Water and Soil Science, Vol. 1, No, 3, pp. 74-86, 2010.

[14] H. Ghoddosy, F. Vakilitanha, and K. Shahverdy, "Application of SCE and LINGO11 in eatrh dam dimensions optimization," Iran Water and Soil Researches, Vol. 42, No. 2, pp. 233-242, 2018. doi: 10.22059/IJSWR.2017. 216401.667541

[15] D.A. El Molla, "Seepage through homogeneous earth dams provided with a vertical sheet pile and formed on impervious foundation," Ain Shams Engineering Journal, Vol. 10, No. 3, pp. 529-539, 2019. doi:10.1016/J.ASEJ.2018.12.008.

[16] A. Mahmoud, X. Yuan, and Y Yuan, "Hybrid meta-heuristic adaptive fuzzy inference systems in rockfill fam multi-objective shape optimization," KSCE Jornal of Civil Engineering, 2021. doi: 10.1007/s12205-021-1504-9.

[17] Iran Water \& Power Resources Co., Geotechnical Report of Sardasht Dam, Iran Ministary of Power, Tehran, Iran, 2012.

[18] U.S. Army Corps of Engineers (USACE), Engineering and Design: General Design and Construction Considerations for Earth and Rock-fill Dams, EM 111 0-2-2300, U.S. Army Corps of Engineers, Washington, United States, 2004. doi:10.1007/s00405-012-1969-8. 
[19] J. Kennedy, and R. Eberhart, "Particle swarm optimization," Paper presented at Proceedings of ICNN'95 - International Conference on Neural Networks, 1995, doi:10.1109/ICNN.1995.488968.

[20] C.A.C. Coello, G.T. Pulido, and M.S. Lechuga, "Handling multiple objectives with particle swarm optimization," IEEE Transactions on Evolutionary Computation, Vol. 8, No. 3 pp. 256-279, 2004. doi:10.1109/TEVC.2004.826067.

[21] C.A.C. Coello, and M.S. Lechuga, "MOPSO: A Proposal for multiple objective particle swarm," Paper presented at Proceedings of the 2002 Congress on Evolutionary Computation. CEC'02 (Cat. No.02TH8600), 2002, doi: 10.1109/CEC.2002.1004388.

[22] N. Srinivas, and K. Deb. "Muiltiobjective optimization using nondominated sorting in genetic algorithms," Evolutionary Computation, Vol. 2, No. 3, pp. 221-248, 1994. doi:10.1162/evco.1994.2.3.221.

[23] K. Deb, A. Pratap, S. Agarwal, and T. Meyarivan, "A fast and elitist multi-objective genetic algorithm: NSGA-II," IEEE Transactions on Evolutionary Computation, Vol. 6, No. 2, pp. 182-197, 2002. doi:10.1109/4235.996017.

[24] H. Jain, and K. Deb. "An evolutionary many-objective optimization algorithm using reference-point based nondominated sorting approach, Part II: Handling constraints and extending to an adaptive approach," IEEE Transactions on Evolutionary Computation, Vol. 18, No. 4, pp. 602-622, 2014. doi:10.1109/TEVC.2013.2281534.

[25] K. Deb, and H. Jain, "An evolutionary many-objective optimization algorithm using reference-point-based nondominated sorting approach, Part I: Solving problems with box constraints," IEEE Transactions on Evolutionary Computation, Vol. 18, No. 4, pp. 577-601, 2014. doi:10.1109/TEVC.2013.2281535.

[26] C.A.C. Coello, G.B. Lamont, D.A. Van Veldhuizen, Evolutionary Algorithms for Solving Multi-Objective Problem, $2^{\text {nd }}$ Edition, Springer, Boston, United States, 2007. doi:10.1007/978-0-387-36797-2_1.

[27] C.A.C. Coello, and M. Reyes Sierra, "A study of the parallelization of a coevolutionary multi-objective evolutionary algorithm," Paper presented at Mexican International Conference on Artificial Intelligence, 2004, doi:10.1007/978-3-54024694-7_71.

[28] D.A. Van Veldhuizen, and G.B. Lamont, "Multi-objective evolutionary algorithms: analyzing the State-of-the-Art," Evolutionary Computation, Vol. 8, No. 2, pp. 125147, 2000. doi:10.1162/106365600568158.

[29] L.C.T. Bezerra, M. López-Ibáñez, and T. Stützle, "An empirical assessment of the properties of inverted generational distance on multi- and many-objective optimization," Paper presented at Lecture Notes in Computer Science (including subseries Lecture Notes in Artificial Intelligence and Lecture Notes in Bioinformatics), 2017, doi:10.1007/978-3-319-54157-0_3.

[30] L. While, P. Hingston, L. Barone, and S. Huband, "A faster algorithm for calculating Hypervolume," IEEE Transactions on Evolutionary Computation, Vol. 10, No. 1, pp. 29-38, 2006. doi:10.1109/TEVC.2005.851275.

[31] J. Zatarain Salazar, P.M. Reed, J.D. Quinn, M. Giuliani, and A. Castelletti, "Balancing exploration, uncertainty and computational demands in many objective reservoir optimization," Advances in Water Resources, Vol. 109, pp. 196-210, 2017. doi:10.1016/j.advwatres.2017.09.014.

[32] Y. Cui, Z. Geng, Q. Zhu, and Y. Han, "Review: Multi-objective optimization methods and application in energy saving," Energy, Vol. 125, pp. 681-704, 2017. doi: 10.1016/j.energy.2017.02.174.

[33] X. Liao, Q. Li, X. Yang, W. Zhang, and W. Li, "Multi-objective optimization for 
crash safety design of vehicles using stepwise regression model," Structural and Multidisciplinary Optimization, Vol. 35, No. 6, pp. 561-569, 2008. doi:10.1007/s00158-007-0163-x.

[34] K. Deb, L. Thiele, M. Laumanns, and E. Zitzler, "Scalable test problems for evolutionary multiobjective optimization, In Evolutionary Multiobjective Optimization. Advanced Information and Knowledge Processing, A. Abraham, L. Jain, and R. Goldberg, eds.: Springer, London, United Kingdom, pp. 105-145, 2005. doi: 10.1007/1-84628-137-7_6.

[35] Y. Tian, R. Cheng, X. Zhang, and Y. Jin, "PlatEMO: A MATLAB platform for evolutionary multi-objective optimization [Educational Forum]," IEEE Computational Intelligence Magazine, Vol. 12, No. 4, pp. 73-87, 2017. doi:10.1109/MCI.2017.2742868.

[36] O. Cuate, L. Uribe, A. Lara, and O. Schütze, "Dataset on a benchmark for equality constrained multi-objective optimization," Data in Brief, Vol. 29, pp. 105130, 2020. doi:10.1016/j.dib.2020.105130.

[37] J. Zhu, H. Chen, G. Wu, L. Chen, and H. Li, "Pressure point driven evolutionary algorithm for many-objective optimization," Swarm and Evolutionary Computation, Vol. 51, pp. 100599, 2019. doi:10.1016/j.swevo.2019.100599.

[38] Z. Chen, Y. Zhou, and X. He, "Handling expensive multi-objective optimization problems with a cluster-based neighborhood regression model," Applied Soft Computing Journal, Vol. 80, pp. 211-225, 2019. doi:10.1016/j.asoc.2019.03.049.

[39] E. Guerrero-Peña, and A.F.R. Araújo, "Multi-objective evolutionary algorithm with prediction in the objective space," Information Sciences, Vol. 501, pp. 293-316, 2019. doi:10.1016/j.ins.2019.05.091.

[40] L.P. Cota, F.G. Guimarães, R.G. Ribeiro, I.R. Meneghini, F.B. DeOliveira, M.J.F Souza, and P. Siarry, "An adaptive multi-objective algorithm based on decomposition and large neighborhood search for a green machine scheduling problem," Swarm and Evolutionary Computation, Vol. 51, pp. 100601, 2019. doi:10.1016/j.swevo.2019.100601.

[41] X. Liu, Y. Zhou, J. Zhao, R. Yao, B. Liu, D. Ma, and Y. Zheng, "Multi-objective ResNet pruning by means of EMOAs for remote sensing scene classification," Neurocomputing, Vol. 381, pp. 298-305, 2019. doi:10.1016/j.neucom.2019.11.097. 